\title{
Simulation of the Thermoforming Process of Glass Fiber Reinforced Polymeric Components: Investigation of the Combined Effect of the Crosshead Speed and Material Temperature
}

Antonios Stamopoulos ( $\sim$ antonios.stamopoulos@univaq.it )

Universita degli Studi Dell'Aquila

Antoniomaria Di llio

Universita degli Studi Dell'Aquila

Luca Glauco Di Genova

Universita degli Studi Dell'Aquila

\section{Research Article}

Keywords: Thermoplastic Composites, Textiles, Unidirectional, Thermoforming

Posted Date: April 13th, 2021

DOl: https://doi.org/10.21203/rs.3.rs-393419/v1

License: (c) (1) This work is licensed under a Creative Commons Attribution 4.0 International License. Read Full License

Version of Record: A version of this preprint was published at The International Journal of Advanced Manufacturing Technology on August 21st, 2021. See the published version at https://doi.org/10.1007/s00170-021-07845-2. 


\section{Abstract}

Thermoplastic based composite materials are increasingly gaining the interest of many engineering sectors, among them the automotive. Their unique features, resulted by the thermoplastic matrix characteristics, such as their recyclability and their formability have given new perspectives in their use. Among the most promising fabrication methods of thermoplastic composite components is the thermoforming process, the press forming of a heated semi-finalized composite plate. This method, although requires a quite simple working station and can be implemented in mass production, demonstrates a series of disadvantages on the quality of the product. Among them, the variation of the thickness, formation of wrinkles and overall undesired deformations are considered as defects that decrease the quality not only from the esthetical but also from the structural point of view. In the present work, a numerical analysis of the thermoforming process is conducted when applied to a box-shaped geometry. As an input for the material behavior during the process, mechanical tests are conducted at elevated temperatures. The flat and curved critical zones of the component are identified and an analysis of the effect of the temperature and the crosshead speed of the molds on the thickness distribution are examined as well as the overall residual stress field. The results indicate a strong dependency of the quality of the product by these parameters of the process.

\section{Introduction}

Nowadays, all the industrial sectors are oriented towards the implementation of advanced materials in several engineering applications aiming to exploit at maximum their potentials. As the design and fabrications methods advanced, the composite materials are being increasingly used either by the aeronautical or the automotive sector. For instance, typical examples of the utilization of composite materials in the aeronautical sector are the Boeing 787 and the Airbus A350 aircrafts, made of composite materials in percentages more than $50 \%$. In the automotive, even though economic and technical problems have risen, the use of composite materials remains an attractive solution for decreasing the vehicle's weight. Therefore, there has been observed a wide range of applications in vehicles including seats, exterior panels, roofs, engine covers or even the chassis [1-2]. It has been reported that for every $100 \mathrm{~kg}$ of weight saving, the consumption reduction is, directly or indirectly, up to $0.7 \mathrm{~L}$ per $100 \mathrm{~km}$ of driving distance [3].

Among the fiber reinforced polymers (FRP), the thermoplastic based ones are an appealing solution, especially for the automotive industry due to the advantages they have compared to the thermosets. Those advantages are mostly practical as they require less demanding storage conditions, they can be processed or reformed as they are recyclable and, from the economical point of view, appear to be more cost-efficient [4-5]. As the thermoset based composites can only be moulded once, the thermoplastic matrix composites can be reheated, reformed, and recycled, increasing in parallel the aspect of renewable materials and structures. From the existing variety of thermoplastic matrices, polypropylene (PP) based ones are already used in neat or partially reinforced form in applications in the automotive such as in interior aesthetic components like dashboards, fan blades and other secondary components. The main 
reason is the applicability of easy and cost-efficient fabrication methods such us the injection moulding [6]. Nevertheless, there has been noticed the implementation of a variety of polypropylene products in more complex composite structures such as automotive sunroofs and battery trays [7] which, apart from the aesthetical part, they require a certain structural integrity.

As mentioned above, due to the capability of the thermoplastic composite materials to be reheated and formed accordingly, one of the methods for producing composite components efficiently, in terms of cost, is the thermoforming process. By this method, a semi-finalized thermoplastic composite product in the form of plate, is hot-pressed at a temperature governed mostly by the matrix constituent and, consecutively, cooled at the ambient temperature. The applied pressure and the exposure of the composite plate to the heating sources though is related also to the nature of the reinforcing media as it has to be over the glass transition temperature and heated in a uniform and stable way to give rubbery characteristics to the composite plate. In addition, several other parameters can influence the overall quality of the product such as the stamping speed, the applied pressure, the reinforcing media drapability and the friction between the stamping tools and the composite plate. Consequently, all the abovementioned parameters, can play a key role to the formation of defects that can degrade the produced part both structurally and aesthetically. These defects consist of wrinkles, intense shear deformation of textile composites, residual stresses, decrease of the thickness of the lamina locally and abnormal distribution of the thickness and intense deformation of the textile globally [8].

Usually, the identification of the right process parameters is done by a trial-and-error method. Considering the time and cost consumption of such strategy there has been reported an increasing number of both experimental and numerical investigations of the thermoforming process using several approaches and materials. For instance, Abbassi et al. [9] conducted an experimental and numerical analysis of the hemispherical thermoformed carbon/PPS material. In this case, the experimental procedure was utilized to validate the proposed numerical strategy. Sadighi et al. [10] investigated both numerically and experimentally the effect of the stacking sequence of UniDirectional (UD) glass fiber reinforced polypropylene hemispherical parts, concluding that a $[0,90]$ s configuration tends to demonstrate less wrinkles compared to a [0]s and $[0,90, \pm 45]$ s composite laminates as a result of the different interactions of fiber plies as they are being deformed during the thermoforming process. De Luca et al. [11], back in 1998, conducted an experimental and numerical analysis of the formation of wrinkles in a double coned geometry using both UD and woven textile carbon fiber reinforced thermoplastic polymers (CFRTP). Guzman-Maldonado et al. [12] presented a thermomechanical analysis and simulation of the thermoforming of a PA66/Satin glass into a hemispherical geometry. Haanappel et al. [13] presented a simulation of the thermoforming process of both CFRTP and GFRTP into more complex aeronautical geometries. In all the works mentioned above, the results were also validated by an experimental campaign indicating that the concept of the virtualization and simulation of this process may be the key to deliver accurate results and predictions of the quality of the produced component into a short period of time, also decreasing the cost of a potential experimental approach. Moreover, the identification of potential irregularities of the forming process itself may be identified as seen in [14]. 
Considering the above, there have been noticed even comparisons concerning the accuracy of several finite element software packages [15-16] as the traditional standard FE software packages are not so suitable for delivering accurate results of large deformations easily [17]. Most of the modern FE packages presuppose the knowledge of the material mechanical behaviour when deformed in specific temperatures and deformation speeds. This fact requires complex experimental characterization of the tensile, shear and bending mechanical behaviour or the GFRTPs in temperatures which are, most of the time, near the melting point of them as well as the friction interaction characterization between the composite material and the stamping tools. These tests are widely investigated and implemented in a significant number of works. Among these works mentioned should be those of Chen et al. [18] and Hamila et al. [19] where the objective is the accurate simulation of the deformation of the reinforcing constituent while being formed, Haanappel et al. [20] where the torsion test in elevated temperatures is proposed for characterizing the shear behaviour of thermoplastic composites and Harrison et al. [21-22], as well as Boisse et al. [23], where the efficiency of the bias extension and the picture frame tests is assessed.

In the present work, the same FE strategy is implemented to optimize the thermoforming a box-shaped automotive component made of woven glass fibre reinforced polypropylene. The composite material mechanical behaviour is characterized in three temperatures namely 140,160 and $190^{\circ} \mathrm{C}$ which correspond to a temperature bellow, equal and above the melting point. Moreover, a Uni-directional Eglass/PA6 composite material is considered as an alternative solution for conducting a comparison between the two materials with different polymeric matrix system and fiber architecture. Consecutively, the influence of the synergistic effect of the temperature and the stamping speed on the distribution of the thickness, the stresses and the shear angle is investigated while the critical zones of the component are identified. The results of reveal a strong dependency of the output of the process on the material temperature and the stamping speed both for the case of the woven textile and the UD thermoplastic composite part.

\section{Experimental}

\subsection{Materials}

As previously mentioned, the textile composites are among the most appreciated materials by a lot of industrial sectors. As their mechanical properties exhibit a certain balance between the two principal directions which are reinforced by the fabric, these materials are destined to be implemented in more structural applications. On the other hand, the UD long-fibre thermoplastic composites, due to the absence of second direction of reinforcement, is theoretically more easily deformable. In the present work, both composite materials used are produced directly in sheets and belong to the category of the semifinalized products. This category refers to composite materials produced directly into plates or tubes in a variety of thicknesses and can be later processed utilizing a hot-forming method. Their technical datasheet is presented in Table 1. 
Table 1

The characteristics of the two thermoplastic composite materials as indicated by their technical datasheets.

\begin{tabular}{|llll|}
\hline & & $\begin{array}{l}\text { TEPEX Dynalite } \\
\text { 104-RG600(x)47\% }\end{array}$ & $\begin{array}{l}\text { Celanese Celstran } \\
\text { CFR-TP PA6 GF60-1 }\end{array}$ \\
\hline Reinforcing Constituent & {$[-\%]$} & Twill Weave E-Glass - 47\% & Uni-Directional E-Glass - 60\% \\
\hline Matrix Polymer & {$[-]$} & Polypropylene (PP) & Nylon 6 (PA6) \\
\hline Density & {$\left[\mathrm{kg} / \mathrm{m}^{3}\right]$} & 1680 & 1690 \\
\hline Elastic Modulus & {$[\mathrm{GPa}]$} & 20 & 20.4 \\
\hline Tensile Strength & {$[\mathrm{MPa}]$} & 430 & 275 \\
\hline Strain at break & {$[\%]$} & 2.7 & 1.9 \\
\hline Flexural Modulus & {$[\mathrm{GPa}]$} & 17 & 18.4 \\
\hline Flexural Strength & {$[\mathrm{MPa}]$} & 370 & 455 \\
\hline Melting Temperature & {$\left[{ }^{\circ} \mathrm{C}\right]$} & 163 & $270-295$ \\
\hline
\end{tabular}

The first one is the TEPEX 104 RG600(x)/47\% (Bond Laminates GmbH, Brilon, Germany) which consists of a regular woven $2 / 2$ twill-weave fabric made of E-glass fibres that cover an area weight of $600 \mathrm{~g} / \mathrm{m}^{2}$. The fabric features a weight rate is of $50 \%$ for the warp and the weft direction respectively and reinforce by $47 \%$ volume fraction a polypropylene matrix. This material is known also from previous research either by the measurement of the in-plane shear properties at a wide temperature range [24], or even by the implementation of the picture frame tests at extremely high temperatures above the melting point of the material [25]. In the same work, evident is the influence of the local irregularities such as the fibre roving's interception and interlace to the shear deformation of the composite material in the elevated temperatures. In fact, such type of phenomena is also present in other works dealing with woven or 3D woven textile composites [26].

The second material is the Celanese Celstran CFR-TP PA6 GF60 which is a UD E-glass/ Nylon PA6 system with $60 \%$ fiber content. The technical datasheet of the material is reported in Table 1 alongside with the one of the TEPEX 104 RG600(x)/47\%. The two materials demonstrate similar density, flexural and tensile moduli while, due to the different matrix system, demonstrate different melting points/windows. The TEPEX appears to melt at roughly $160^{\circ} \mathrm{C}$ while the Celstran close to $270^{\circ} \mathrm{C}$ with a much higher deviation on that. Since the material card of the UD material was available a priori by the FE software [13] for the temperatures of 240,260 and $280^{\circ} \mathrm{C}$, the so-called material card of the woven textile E-glass/PP must be created. The temperatures chosen are 140,160 and $190^{\circ} \mathrm{C}$ which correspond to a temperature more than $20{ }^{\circ} \mathrm{C}$ bellow, at and more than $25^{\circ} \mathrm{C}$ above the melting point. The consideration of these temperature is made in a way to have crucial information about the material behavior in the case the temperature, during 
the thermoforming process, drops below the melting point due to convection and conduction loses as seen also in other works [27].

\subsection{Mechanical Characterization at Forming Conditions}

As previously mentioned, the experimental data of the mechanical behavior of the material in forming temperatures are substantial as they are used as input by the corresponding software of the finite element analysis for simulating the thermoforming of the component. Generally, any approach of this kind needs to be fed with this data, regardless the software that is being utilized [28-29]. Since the software of interest used in the present work assumes that the overall deformation of the material is the combined output of a bending and an in-plane shear deformation along with an interaction between the stamping tools and the composite material, a series of mechanical tests have been conducted the test matrix of which is reported in Table 2. The experimental campaign is conducted by the Thermoplastic Composites Research Center (TPRC, Enschede, The Netherlands) in its premises using state-of-the art machines and measuring equipment. All the specimens were subjected in a pre-conditioning for drying them which includes a slight vacuum combined with an imposed temperature of $70^{\circ} \mathrm{C}$ for more than 12 h. Moreover, the temperature below the melting point of the material $\left(140^{\circ} \mathrm{C}\right)$ is of particular interest. In fact, the TEPEX composite material exhibits a melting point of $163^{\circ} \mathrm{C}$ while, after having been melted completely, its solidification point is at roughly $125^{\circ} \mathrm{C}$. Thus, for conducting the tests at $140{ }^{\circ} \mathrm{C}$, the material is heated up to the melting point and then, during the cooling down phase, is tested when reaching the desired temperature. Consequently, apart from the pre-conditioning of the specimens, an additional heating, and a controllable cooling down of $6^{\circ} \mathrm{C} / \mathrm{min}$ is implemented. This procedure is followed for each of the testing methods applied for characterizing this material at $140^{\circ} \mathrm{C}$. 
Table 2

Test matrix of the experimental campaign of the TEPEX 104-RG600(x)47\%

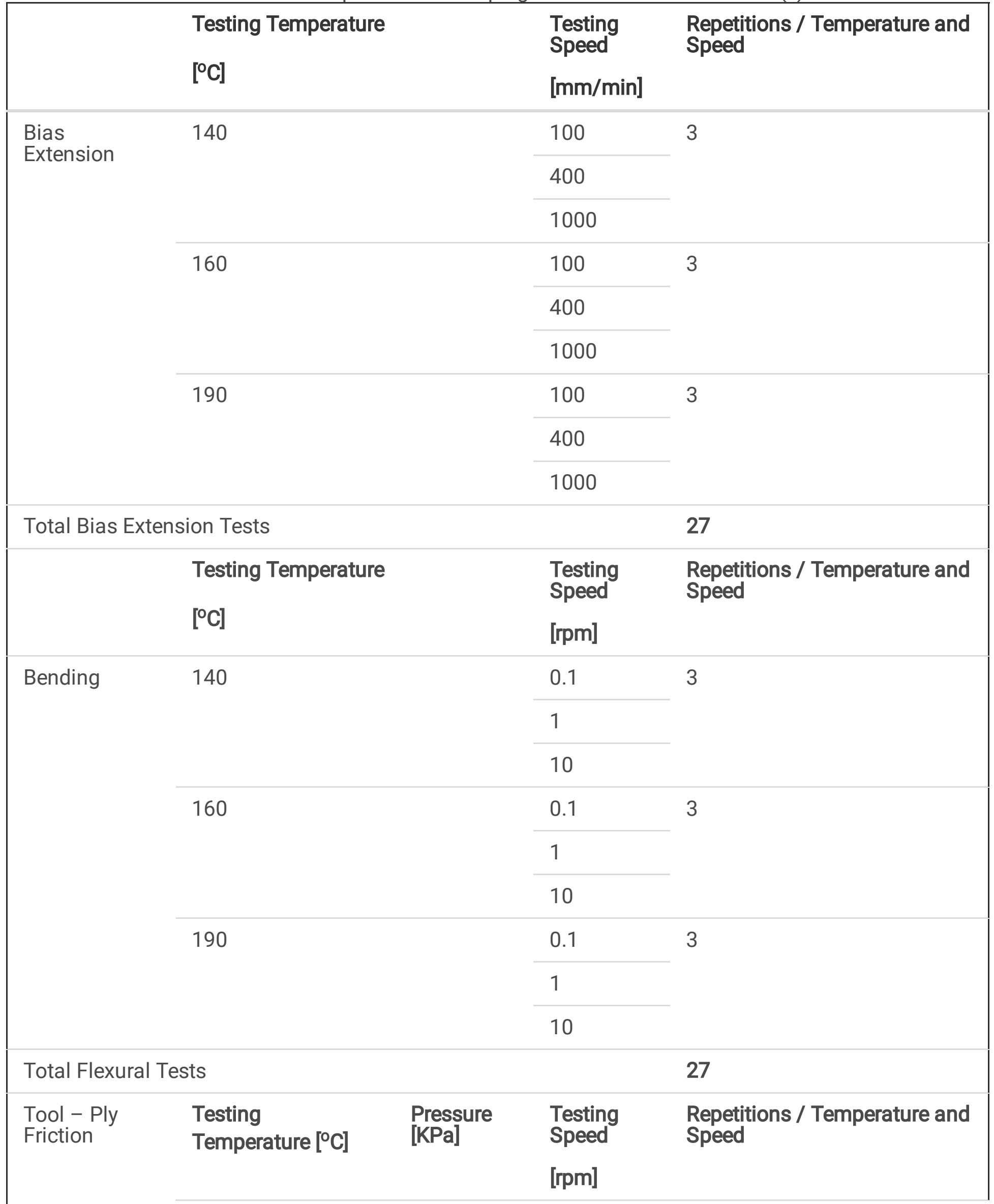




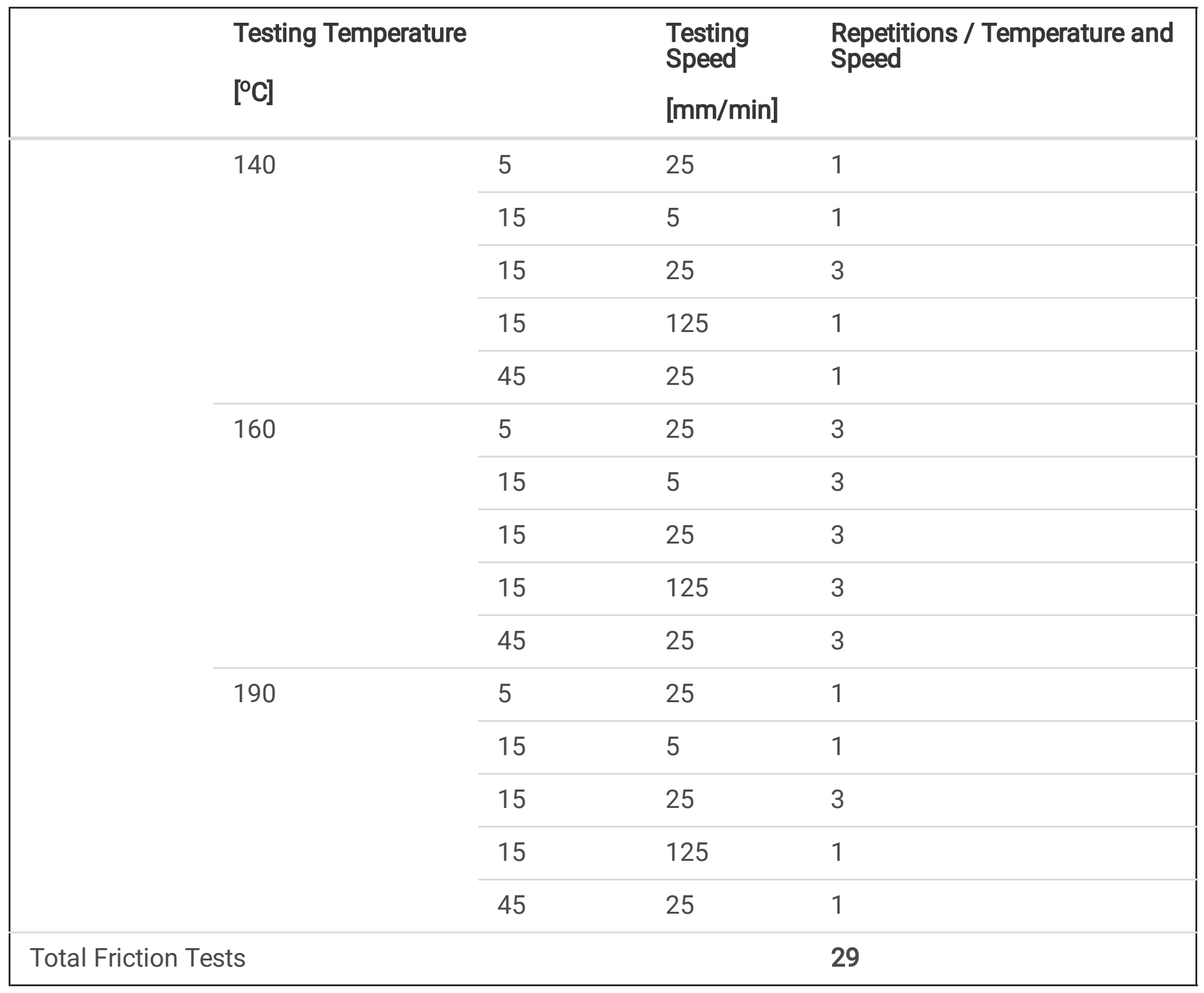

\subsubsection{Bias Extension Tests}

The bias extension test is implemented for characterizing the in-plane shear mechanical behavior of the woven textile E-glass/PP material under various deformation rates. It is based on the ASTM D5035 standard [30] which refers to textile materials without matrix. Nevertheless, compared to other shear testing approaches, it is considered as a robust and simple method to characterize the in-plane shear deformation at high temperatures [31-32]. In the present work, a single-layer balanced plate of the TEPEX $104-R G 600$ (x) $47 \%$ is used for ensuring the purity of the results. In Fig. 1(a) the basic geometry of the specimen used as well as the deformed shape and the individual zones of the specimen are presented. A typical specimen has a length/width aspect ratio of 3 while the textile is inclined $45^{\circ}$ from the principal axis of the specimen. Moreover, the specimen is divided in 3 zones, as seen in Fig. 1(a), based on the purity of the shear deformation during the execution of the tests. As seen in Table 2, a total number of 27 tests are conducted at the 3 temperatures of interest under various deformation rates. The average loaddisplacement curves, accompanied with the corresponding standard deviation, for every temperature and 
testing speed are reported in Fig. 1(b). Observed is a notable difference of the shear behaviour of the textile material at $140^{\circ} \mathrm{C}$, a fact which is explained by the partial solidification of the material. At that temperature, the shear stiffness and is much higher compared to the ones obtained at $160^{\circ} \mathrm{C}$ and $190^{\circ} \mathrm{C}$, respectively.

\subsubsection{Bending Tests}

A total number of 27 bending tests are conducted at the 3 temperatures of interest. Considering that the bending behaviour of a composite material is highly affected by the matrix quality and state, a fixture dedicated in characterizing this behavior at forming temperatures is utilized. Instead of considering a long prismatic composite specimen under 3 or 4-point bending deformation, in the present work a torsional bending test method is implemented, presented in Fig. 2 (a). It consists of a test according to which a rectangular single layered specimen is loosely clammed in a fixture that introduces a bending using a rotational rheometer. This method is found also in previous works [33] and is developed by the University of Twente, the Netherlands. Considering the 2 variables, testing temperature and torsional speed (rpm) for each of the 3 temperatures of interest, there have been applied 3 different testing speeds, namely $0.1,1$ and $10 \mathrm{rpm}$. Moreover, an appropriate conditioning of the climatic chamber and the fixture is applied regarding the temperature. The fixture and the oven utilized, are previously heated up to the temperature of interest while during the execution of the tests the clamps of the fixture are always $10^{\circ} \mathrm{C}$ higher than the material for excluding any local cooling. The results, in terms of average moment-angle deformation are presented in Fig. 2(b). Noted should be the significant superior bending stiffness of the material at $140^{\circ} \mathrm{C}$ and the increasing standard deviation obtained for this particular temperature while the testing speed increases. These two facts are a strong indication of a presumable partial solidification of the composite material at this temperature, even when tested while being cooled down after reaching the melting point. At that temperature, there can be observed higher moment values while the testing speed is decreasing which can be attributed to mainly 2 phenomena; the partial crystallization of the material even if the solidification temperature is lower, and the local buckling of the fibres. On the contrary, at $160^{\circ} \mathrm{C}$, the tests results deviation is much lower, a fact which indicates the reproducibility of the test method at that temperature.

\subsubsection{Dynamic Friction Tests}

As the contact between the stamping tools and the composite material is an indispensable aspect that may introduce additional stresses during the forming process, friction tests are conducted utilizing the Twente configuration which, compared to many others, is able to derive accurate results [34]. The basic parts of this configuration is presented in Fig. 3 (a). This test consists of a single-layered rectangular composite specimen, $200 \mathrm{~mm}$ long and $50 \mathrm{~mm}$ wide, that slides inside a couple of grips at the end of whom there are mounted 2 metallic plates of $120 \mathrm{~mm}$ length and $50 \mathrm{~mm}$ width. The contact area between the metallic tabs and the composite specimen is $60 \mathrm{~mm}$ long and $50 \mathrm{~mm}$ wide. Throughout the execution of the tests, the grips temperature is controlled as well as the applied pressure. Therefore, there are 3 parameters that are taken into consideration, namely the testing speed, the testing temperature, and the applied pressure, as presented in Table 2. The average shear stress-displacement curves for the 3 
temperatures of interest and various testing speeds are presented in Fig. 3 (b) for applied pressure of 5 kPa, Fig. 3(c) for $15 \mathrm{kPa}$ and Fig. 3 (d) for $45 \mathrm{kPa}$ respectively. Observed is a much higher peak stress value for the tests conducted at $140^{\circ} \mathrm{C}$ compared to the rest of the temperatures at any speed-pressure combination. Moreover, the steady stress state after the peak stress is comparatively lower compared to the maximum stress value for the tests conducted at $140^{\circ} \mathrm{C}$. The combination of those two observations is a strong indication of a partial solidification of the composite material at the abovementioned temperature.

\section{Finite Element Simulation}

\subsection{Tools and Fixtures Design}

The geometry of the component is an inverse $\Omega$ shaped part. Its dimensions are roughly $334 \mathrm{~mm}$ long and $296 \mathrm{~mm}$ wide. The depth of the box, and thus the maximum distance from the top surface to the bottom is $248 \mathrm{~mm}$ from one side and 220 from the other, while the bottom surface is $174 \mathrm{~mm}$ long and $290 \mathrm{~mm}$ wide. One of the most challenging aspects is the almost perpendicular sides of the box $\left(92^{\circ}\right)$ which, combined with the significant depth of the component, makes quite difficult the forming process. The components basic geometrical and dimensional characteristics are presented in Fig. 4. For performing the simulation, the stamping tools and the composite material plate are designed in CATIA V5 software. At this point, assumed is a complete and perfect closing of the moulds, a fact which practical means that the gap between the stamping tools at the final stage of the process is equal to the composite plates thickness. Moreover, a supporting fixture is designed to support the necessary auxiliary equipment for the thermoforming process such as tensioners. The complete design of the stamping tools, the composite plate and the auxiliary fixture are presented in Fig. 5 (a). Finally, the composite plate is not perfectly rectangular as the top part of the component is wider than the bottom. A potentially rectangular composite plate can potentially introduce additional problems to the forming process. Thus, the composite plate is considered as seen in Fig. 5 (b) and has a shape which is imposed by the geometrical restrictions of the final product.

\subsection{Finite Element Analysis}

The FE package utilized in the present work is the AniForm ${ }^{\circledR}$ FE code which adopts an implicit solver and a continuum mechanical formulation [35-36]. The shell elements utilized by the software combine the properties included in a LTR3D element and a Discrete Kirchhoff Triangle, consisting of 3 nodes each while the difference between them is the degrees of freedom; the DKT shell comprises 6 while the LTR3D membrane 3 each. To this end, all the information about the material behaviour, including both the inplane and bending, acquired experimentally, are integrated in the FE model configuration consisting of different material models. Another aspect, which is worthwhile to mention, is the contact between the stamping tools and the lamina. This contact, which includes the friction between the stamping tools and the lamina described by the output experimental campaign presented in Sect. 2.2.3, is applied by using the corresponding master and slave contact elements. The master (CMasterLTR3D) and slave 
(CSlaveLTR3D) triangular contact elements are created automatically using the Hammer projection technique as seen in Fig. 6 (a) in which the slave contact elements search for projections from their quadrature point locations. This way, while the bodies are moving on the surface of the slave elements both in and out-of-plane traction is created while the master do not take as input any material model. Also, an offset is applied to the contact elements so that the contact surface is transferred from the element mid-plane to the actual contact surface, an operation which is imposed explicitly as seen in Fig. 6 (b). For avoiding the penetration, a penalty stiffness is introduced, and the contact pressure $\tau_{n}$ can be expressed as:

$$
\tau_{n}=E_{p} \delta
$$

1

where $E_{p}$ is the penalty stiffness and $\delta$ is the penetration depth. The overall traction developed on the surface of the slave element is calculated by the summary of the introduced shear stress and the contact pressure:

$$
\tau=\tau_{x y}+E_{p} \delta
$$

As previously mentioned, the materials used for the simulations are 2, namely the Dynalite TEPEX 104RG600(x)47\% (twill 2/2 weave glass/polypropylene) and the Celanese Celstran CFR-TP PA6 GF60-1 (UD glass/PA6). The TEPEX material constitutive laws were obtained by the mechanical testing campaign described in Sect. 2 of the present work, while the Celstran was one of the materials available in the software library. For creating the material card of the material, a MatLab based sub-rootine is utilized (AniForm MatFit) for producing the regression curves of the mechanical behaviour of the composite material (TEPEX 104-RG600(x)47\%) (37). As seen in their technical datasheets in Table 1, the 2 materials exhibit similar mechanical properties in ambient temperature in the fiber direction as they both have glass fibres as the reinforcing constituent. Yet, apart from the fact that the first one is a balanced woven textile and the second one is a UD, they have two other significant differences; the matrix material (PP for the TEPEX and Nylon 6 for the Celanese Celstran) and the fibre content (47\% for the TEPEX and $60 \%$ for the Celanese Celstran). As a result, the two materials have different melting points and melting temperature windows. Consequently, different forming temperatures are considered for the two materials keeping also the same principal consideration about the forming temperatures. To this end, in both cases three temperatures are considered, one slightly below the nominal melting temperature, one at the melting point of the material and one slightly above it, as explained also in the experimental campaign of the TEPEX 104RG600(x)47\%. The corresponding material models imposed in each case are summarized in Table 2 and Table 3 for the TEPEX and the Celstran respectively. As seen there, for the two materials there are some differences on the material models used for describing the in-plane and bending behaviours while the material model for the contact are the same. At this point, it should be indicated that the values of the parameters $\mu$ and $n_{0}$ respectively are defined by the tool-ply friction tests described in Sect. 2.2.3 of the 
present work while the penalty stiffness has a value which excludes any element penetration without interfering on the numerical stability and convergence of the finite element model. On the other hand, the stamping tools and the supporting fixing tools are considered as rigid while, for avoiding the development of wrinkles during the stamping process, 2 couples of springs delivering $0.19 \mathrm{~N} / \mathrm{mm}$ each, are placed in the zones identified as crucial. Their direction is perfectly aligned to the direction of the fibres (for the case of the UD Celanese Celstran) and the warp direction of the textile (for the case of the TEPEX) respectively. Other fundamental assumptions made using this software is the fact that the temperature during the process remains constant. In addition, the cooling down process after the stamping is neglected. Thus, the results obtained may be correlated with the step just before the cooling down of the final product. The mesh density and overall number is chosen after conducting a parametric study in which the computational time and the accuracy were considered. Each finite element model consists of 107030 elements from which 23350 (11390 nodes) are attributed to the composite plate and 83680 (43301 nodes) to the stamping tools. Details of the mesh discretization are presented in Fig. 7 while frames during the process simulation are presented in Fig. 8. For each of the reference temperatures of each material described previously, 4 different crosshead speeds are considered, namely 30, 45, 90 and $200 \mathrm{~mm} / \mathrm{s}$, delivering a total number of 24 simulations, 12 for each of the materials. The time needed for solving each model, using a computer composed of the Intel i9-9900x series 10-core processor and 128GB RAM, varies from 15 to 30 minutes.

\section{Results}

Regarding the results, the FE package provides either a graphical distribution of some properties, or a report of the values for each of the nodes of the model. This fact was also considered during the discretization of the models; the mesh is dense enough to produce enough points from which the desired values of thickness or stress can be obtained. Therefore, in this section the results are presented both in terms of 3D distribution and graphs. For achieving this, the reports are elaborated using a script developed in MatLab in which slices of the model in the xz plane can be cut and deliver this way the distribution in a more localized zone. In all the cases, examined is the distribution of the thickness, the shear strain, and the residual stresses in the lowest part of the component (where the pressure is expected to be higher) as well as the lateral walls of the box and the upper surfaces. The zones taken into consideration are those presented in Fig. 9, considered in the half of the component towards the $y$ axis due to the symmetry of the component. Considering the geometrical complexity of the component studied in the present work, it was divided into these 3 zones of interest that consist of 1 zone at the center (Zone 1) with 2 irregularities, 1 zone without any geometrical interference (Zone 2 ) and 1 zone with an elongated geometrical oval-shaped bulge (Zone 3). These zones are the most indicative and representative of the whole structure as they are among the most critical ones as seen in the following sections. It should be noted that phenomena such as the presence of wrinkles are not severe as the tensioners and the right textile orientation are preventing them and in the final product, considering the perfect closing of the stamping tools, there is none. Nevertheless, some local waviness is observed in the first parts of the simulation as the punching tool pushes down the composite plate, as seen also in Fig. 8, which is not present at the end of the process. 


\subsection{Thickness Variation}

One of the main concerns of each composite component produced by thermoforming process is the variation of thickness which is sometimes undesired as it exceeds the limitations and tolerances imposed by the application. This variation may be the result of the non-uniformity of the applied pressure as the surfaces in direct front contact with the stamping tools are expected to receive more compared to any lateral surfaces [14]. In some cases this phenomenon may be more complicated if parameters such as the stamping speed and the temperature of the composite plate are considered.

In Fig. 10, a typical example of the correlation between the distinct parts of the central zone (Zone 1) of the component and the variation of the thickness throughout the $x$ direction is presented, using the 2-2 twill weave E-glass/composite material thermoformed at $140{ }^{\circ} \mathrm{C}$ with $30 \mathrm{~mm} / \mathrm{s}$ stamping speed. As seen there, it is obvious that the upper parts, the lateral walls, and the lower part of the component exhibit different values of thickness. The overall variation of the thickness for the case of the TEPEX Dynalite 104-RG600(x)47 at the 3 reference temperatures and 4 stamping speeds is presented in Fig. 11 for all the zones examined. Observed is, starting from reference thickness of $0.5 \mathrm{~mm}$ (single layer), that the increment of speed seems to decrease the thickness of the component, especially in the lower part of it which is perpendicular to the stamping tool's front. Generally, the thickness variation appears to follow a pattern, as described below:

- The upper part is close to the nominal value of thickness as it is the part of the component that comes into contact with the stamping tool last.

- The lateral walls have values lower compared to the initial thickness which tend to be decreased from top to the bottom of it.

- The lowest part, that it is in contact with the punch tool continuously from the start to the end of the process, appears to have the lowest values of thickness.

- The curved zones of the component appear to have higher values of thickness compared to the flat parts in vicinity.

As the thickness of the upper part of the component remains close to the nominal value of 0.5 in each case, the most intense deviation is localized in the lateral walls the lower part of the component. More precisely, the zone that seems to derive the maximum deviation from the nominal thickness is Zone 3 , especially in the curved part right before the lower flat part. The abovementioned pattern is visible by observing the thickness distribution map of the component in Fig. 12. Both Fig. 11 and Fig. 12 are useful for assessing the synergistic effect of the material temperature and the crosshead displacement of the stamping tools on the variation of the thickness of the single-ply composite material.

For the case of the UD Celanese Celstran CFR-TP PA6 GF60-1, similar observations are extracted only for the central Zone as seen in Fig. 13. The rest of the zones (Zone 2 and 3) follow a slightly different pattern compared to the textile material. The lateral walls exhibit thickness values relatively lower than the nominal ones while the bottom part is quite close to the nominal plate thickness. Nevertheless, by 
observing the overall map of the thickness distribution of Fig. 14, observed is an accumulation of material in the curvatures of the lateral walls while the critical zones remain those having intense geometrical irregularities, perpendicular to the movement of the stamping tools as well as zones with intense curves. Moreover, by comparing the thickness variation of Fig. 14 and the maximum and minimum values in Fig. 15, there can be observed that the increment of the temperature favours the increment of the dispersion of the thickness values, while the increment of stamping speed seems to have a positive effect on that phenomenon. Finally, by comparing the two materials, there can be observed a much higher variation of the obtained values of thickness for the UD composite, the reference sheet thickness of which is $0.3 \mathrm{~mm}$.

\subsection{Stress Analysis}

Another interesting aspect that could be considered for assessing the effect of the synergy of temperature and stamping speed is the stress state of the component. These stresses, as previously mentioned, correspond to the those which are acting on the component after the complete closing of the dies. In Fig. 16 the typical map of the distribution of the normal and in-plane shear stresses is presented for the case of the 2 materials as seen at the FE simulations performed at the lowest temperature and stamping speed. The critical zone appears to be the central one, which corresponds to the Zone 1 of Fig. 9. An interesting observation is the low compressive stresses which can be interpreted as an outcome that indicates the absence of wrinkles as high values of compressive stress are required to form such kind of defects. Across that zone, a typical distribution of the stresses follows the pattern seen in Fig. 17 in which the stress field $\sigma_{x}$ in direction parallel to the principal direction of the fibers (and in the warp direction in the case of the textile). The stresses are relatively low at the upper part of the component (indicated inside the red box of the Fig. 17), are increasing almost linearly at the lateral walls and obtain the maximum values at the lowest part of the component.

Considering the above, the distribution of the normal stresses $\left(\sigma_{x}, \sigma_{y}\right)$ as well as the in-plane shear stress $\left(\tau_{x y}\right)$ across the central zone are presented graphically in Fig. 18 and Fig. 19 for both the woven textile glass/PP and the UD glass/PA6 materials, respectively. The distribution of the 2 materials follows almost the same trend, especially for the case of the normal stress $\sigma_{x}$. Their main difference is the normal stresses $\sigma_{y}$ development and distribution which, for the case of the Celstran, is almost negligible. Moreover, both of them exhibit low shear stress values in this particular zone. In addition, in the same stamping speed, the textile material always delivers higher values of stresses in all of the temperatures of reference compared to the UD. A notable observation is the influence of the temperature and the stamping speed on the residual stresses. As seen in both Fig. 18 and Fig. 19, by increasing the material temperature the stresses are decreasing and the influence of the stamping speed becomes more evident. For instance, by observing the normal stresses of the woven textile material, it is evident a significant increment in the deviation between the maximum values between the individual stamping speeds as the temperature increases. The maximum values of stress reported by each simulation are presented in Fig. 20. Those of the Celstran are comparatively lower to the textile, in fact the maximum $\sigma_{x}$ stress is more than $50 \%$ lower while the $\sigma_{y}$ and $\tau_{x y}$ are almost negligible compared to those of the TEPEX. By observing the results of 
Fig. 20, there can be noted that in both materials, the increment of the material temperature relieves the stresses imposed by the stamping process while the increment of the stamping speeds augments the stresses introduced to the component.

\subsection{Fiber Shear Deformation of the Woven Textile Thermoplastic Composite}

Among the output of the simulation campaign is the distribution of the shear angle of the composite material which corresponds to the angular deformation, $\mathrm{d} \theta$, calculated as:

$$
d \theta=2\left(\phi_{1}-\phi_{0}\right)
$$

3

where $2 \varphi_{1}$ is the final angle between the warp and weft yarns and $2 \varphi_{0}$ the initial one, respectively [37]. This distribution is a strong indication about the deformation of the woven textile composite material. Values close to 0 indicate an undeformed textile while the macroscopic distribution of the shear angle may indicate potential in-plane waviness. Considering this, the shear angle distribution concerns not only the structural part (residual shear deformation of the textile) but also the aesthetical one in case the produced component has to serve without any over-injection that can potentially hide it. As seen in Fig. 21 , the highest positive and negative values are attributed to the zones of the component which are demonstrating intense geometrical irregularities. Nevertheless, the temperature is a key factor for containing the shear angle in small values as seen in Fig. 22. As reported also by the authors of previous work (24)], the shear angle distribution is strongly related to the bending and shear stiffness of the material. Thus, as the influence of temperature is detrimental on both of these properties, at $190{ }^{\circ} \mathrm{C}$ the component has more irregular distribution compared to the one at $140^{\circ} \mathrm{C}$. On the contrary, the stamping speed does not affect the shear angle significantly as there have not been observed any significant variations while the speed increases from $30 \mathrm{~mm} / \mathrm{s}$ at $200 \mathrm{~mm} / \mathrm{s}$.

\section{Conclusions}

In the present work, a finite element simulation campaign was conducted based on a viscoelastic approach that aimed to predict the outcome of the thermoforming of a single plied box-shaped component, using both a woven textile E glass/PP and a UD E glass/PA6 material. A priori, an experimental campaign was conducted for producing the necessary input of the E glass/PP composite for the FE software. The effect of the stamping speed and temperature of the composite material was addressed for assisting the decision making of these parameters at the phase before the realization of a component of this kind.

In the context of the present work, the possibility of utilizing a twill weave E-glass/PP and a UD Eglass/PA6 for producing a box-shaped automotive component was investigated under different deformation rates and in a variety of temperatures. Especially in the case of the textile composite, it was 
considered a temperature which corresponds to a state in which the material is partially solidified, even though the experimental campaign was conducted at the cooling down phase. Consequently, the shear and bending stiffness of it at $140{ }^{\circ} \mathrm{C}$ resulted much higher compared to the other temperatures. Moreover, the dynamic friction curve that describes the contact between the stamping tools and the composite plate appears to have a different tendency compared to the other temperatures, delivering higher values of stress. Generally, the increment of the material temperature contributes to the decrease of the maximum tensile and compressive stresses while increases both the thickness variation and the textile shear deformation. On the contrary, the increment of the stamping speed appears to have a negative effect in roughly all the output (stress, thickness, and shear textile deformation). In addition, by comparing the two materials used, the critical zones are partially the same considering that the UD material appears to be more easily deformable due to the absence of reinforcement in the y direction. Even though the geometrical characteristics of the component are the cause of those critical zones, there have been noticed some differences mainly the thickness variation and the stress distribution between the results from the textile and the UD composite, respectively. Also, both the 2 materials exhibit different sensitivity

on these characteristics in some of the zones of the component. Therefore, by analyzing and comparing the obtained results in terms of thickness variation, stress distribution and fiber shear angle, for each of the combinations of material temperature and stamping speed, valuable observations can be obtained that contribute to the optimal decision of both parameters.

Finally, considering the quite short time needed for the simulation result convergency, the procedure presented previously for defining the parameters of the process can be considered as a step forward to the virtualization of the thermoforming process itself, saving a lot of time and reducing the cost of its development, since it was based until recently in trial-and-error experimental procedures.

\section{Declarations}

\section{Acknowledgements}

The present work has received funding by the national Italian research project C.R.AB (Composites Research Abruzzo) under the auspicies of the Region of Abruzzo (Italy) and the European Union (POR FESR Abruzzo 2014-2020 - ASSE I- Attività 1.1.1 e 1.1.4, contract CAR n.2617-COR n.217245). The authors also wish to express their sincere appreciation for the collaboration with the Thermoplastic Composites Research Center (TPRC) in the Netherlands on the execution of the experimental campaign.

\section{Funding}

This work was supported by the Italian research project C.R.AB (Composites Research Abruzzo) under the auspices of the Region of Abruzzo (Italy) and the European Union (POR FESR Abruzzo 2014-2020 - ASSE I- Attività 1.1.1 e 1.1.4, contract CAR n.2617-COR n.217245). 
Ethics Approval

All procedures performed in studies involving human participants were in accordance with the ethical standards of the institutional and/or national research committee and with the 1964 Helsinki declaration and its later amendments or comparable ethical standards.

\section{Competing Interests}

The authors have no conflicts of interest to declare that are relevant to the content of this article.

\section{Authors' Contribution}

- Antonios Stamopoulos: Research, Data acquisition and Analysis, Document preparation and review.

- Luca Glauco Di Genova: Research, Data acquisition.

- Antoniomaria Di llio: Funding, Data Analysis, Document preparation and review.

\section{Consent to Participate}

The authors consent to participate.

\section{Consent for Publication}

Informed consent was obtained from all individual participants included in the study.

\section{Availability of Data}

The datasets generated and analyzed during the current study are not publicly available due to restrictions imposed by the funding scheme but are available from the corresponding author upon request.

\section{References}

1. Gupta G, Kumar A, Tyagi R, Kumar S (2016) Application and Future of Composite Materials: A Review. International Journal of Innovative Research in Science Engineering Technology 5(5):69076911. doi:10.15680/IJIRSET.2016.0505041

2. Nickels L (2019) New innovations in automotive thermoplastics. Reinf Plast 63(4):185-188. doi:10.1016/j.repl.2019.06.041

3. Patel M, Pardhi B, Chopara S, Pal M (2018) Lightweight Composite Materials for Automotive - A Review. International Research Journal of Engineering Technology 5(11):41-47

4. Stewart R (2011) Thermoplastic composites-recyclable and fast to process. Reinf Plast 55(3):22-28. https://doi.org/10.1016/S0034-3617(11)70073-X

5. Cogswell FN (1992) Thermoplastic aromatic polymer composites. Butterworth-Heinemann, ISBN 9780750610865 
6. Campbell FC (2004) Manufacturing processes for advanced composites. Elsevier Science, ISBN 9781856174152

7. Nickels $L$ (2019) New innovations in automotive thermoplastics. Reinf Plast 63(4):185-188. https://doi.org/10.1016/j.repl.2019.06.041

8. Ashter SA (2014) Thermoforming of single and multilayer laminates. William Andrew Publishing, ISBN 9781455731725

9. Abbassi F, Elfaleh I, Mistou S, Zghal A, Fazzini M, Djilali T (2011) Experimental and numerical investigations of a thermoplastic composite (carbon/PPS) thermoforming. Structural Control Health Monitoring 18:769-780. https://doi.org/10.1002/stc.491

10. Sadighi M, Rabizadeh E, Kermansaravi F (2008) Effects of laminate sequencing on thermoforming of thermoplastic matrix composites. J Mater Process Technol 201:725-730. https://doi.org/10.1016/j.jmatprotec.2007.11.239

11. De Luca P, Lefebure P, Pickett AK (1998) Numerical and experimental investigation of some press forming parameters of two fibre reinforced thermoplastics: APC2-AS4 and PEI-CETEX. Compos Part A: Appl Sci Manufac 29A:101-110. https://doi.org/10.1016/S1359-835X(97)00060-2

12. Guzman-Maldonado E, Hamila N, Boisse P, Bikard J (2015) Thermomechanical analysis, modelling and simulation of the forming of pre-impregnated thermoplastic composites. Compos Part A: Appl Sci Manufac 78:211-222. https://doi.org/10.1016/j.compositesa.2015.08.017

13. Haanappel SN, Ten Thije RHW, Sachs U, Rietman B, Akkerman R (2014) Formability analyses of unidirectional and textile reinforced thermoplastics. Compos A 56:80-92. https://doi.org/10.1016/j.compositesa.2013.09.009

14. Stamopoulos AG, Spitilli P, D’Emilia G, Gaspari A, Natale E, Di llio A (2020) Assessment of the measurements contribution on composites thermoforming processes: a case study of an automotive component. 2020 IEEE International Workshop on Metrology for Industry 4.0 \& loT, 14-16 June 2020, Rome, Italy. 10.1109/Metrolnd4.0loT48571.2020.9138197

15. Dorr D, Brymerski W, Ropers S, Leutz D, Joppich T, Karger L, Henning F (2017) A benchmark study of finite element codes for forming simulation of thermoplastic UD-tapes. Procedia CIRP 66:101-106. https://doi.org/10.1016/j.procir.2017.03.223

16. Stamopoulos AG, Di llio A (2019) On the Predictive Tools for Assessing the effect of manufacturing defects on the mechanical properties of composite materials. Procedia CIRP 79:563-567. https://doi.org/10.1016/j.procir.2019.02.108

17. Ten Thije RHW, Akkerman R, Huetink J (2007) Large deformation simulation of anisotropic material. Comput Methods Appl Mech Eng 196(33-34):3141-3150. https://doi.org/10.1016/j.cma.2007.02.010

18. Chen QQ, Boisse P, Hamila N, Saouab A, Park CH, Breard D (2009) A finite element method for the forming simulation of the reinforcements of thermoplastic composite. IntJ Mater Form 2(1):213216. https://doi.org/10.1007/s12289-009-0655-x 
19. Hamila N, Boisse P, Sabourin F, Brunet M (2009) A semi-discrete shell finite element for textile composite reinforcement forming simulation. Int J Numer Meth Eng 79:1443-1466. https://doi.org/10.1002/nme.2625

20. Haanappel SP, Akkerman R (2014) Shear characterization of uni-directional fibre reinforced thermoplastic melts by means of torsion. Compos A 56:8-26.

https://doi.org/10.1016/j.compositesa.2013.09.007

21. Harrison P, Clifford MJ, Long AC (2004) Shear characterization of viscous woven textile composites: a comparison between picture frame and bias extension experiments. Composites Science Technology 64:1453-1465. https://doi.org/10.1016/j.compscitech.2003.10.015

22. Harrison P, Alvarez MF, Anderson D (2018) Towards comprehensive characterization and modelling of the forming and wrinkling mechanics of engineering fabrics. Int J Solids Struct 154:2-18. https://doi.org/10.1016/j.ijsolstr.2016.11.008

23. Boisse P, Hamila N, Guzman-Maldonado E, Madeo A, Hivet G, Dell'Isola F (2017) The bias-extension test for the analysis of in-plane shear properties of textile composite reinforcements and prepregs: $A$ review. International Journal of Materials Forming 10:473-492. https://doi.org/10.1007/s12289016-1294-7

24. Di llio A, Di Genova LG, Stamopoulos A (2021) Implementation of the modified V-Notched Rail Shear method for characterizing glass fiber thermoplastic composites at sub-zero and elevated temperatures. Polym Testing 93:106874. https://doi.org/10.1016/j.polymertesting.2020.106874

25. Mattner T, Korbel W, Wrensch M, Drummer D (2018) Compensation of edge effects of picture frame testing of continuous fiber reinforced thermoplastics. Composites Part B 142:95-101. https://doi.org/10.1016/j.compositesb.2018.01.009

26. Sharma SB, Sutcliffe MPF, Chang SH (2003) Characterization of material properties for draping of dry woven composite material. Composites Part A 34:1167-1175. https://doi.org/10.1016/j.compositesa.2003.09.001

27. Xiong H, Hamila N, Boisse $P$ (2019) Consolidation modelling during thermoforming of thermoplastic composite prepregs. Materials 12(18):2853. https://doi.org/10.3390/ma12182853

28. Althammer F, Iwan S, Mueller S, Troelzsch J, Kroll L (2017) Simulating the forming of thermoplastic, fiber reinforced plastics-Demonstrated for a side impact protection bar. KMUTNB International Journal of Applied Science Technology 10(2):133-143. 10.14416/j.ijast.2017.05.006

29. Fiumarella D, Boria S, Belingardi G, Scattina A (2019) Experimental and numerical analysis of a thermoplastic lamina for composite material. Procedia Structural Integrity 24:11-27. https://doi.org/10.1016/j.prostr.2020.02.002

30. ASTM D5035-06 (2008) Standard Test Method for Breaking Force and Elongation of Textile Fabrics (Strip Method). ASTM International, West Conshohocken

31. Cao J, Akkerman R, Boisse P, Chen J, Cheng HS, de Graaf EF, Gorczyka JL, Harisson P, Hivet G, Launay J, Lee W, Liu L, Lomov SV, Long A, Morestin F, Padvoiskis J, Peng XQ, Sherwood J, Tao STz, Verpoest XM, Willems I, Wiggers A, Yu J, Zhu TX B (2008) Characterization of mechanical behavior 
of woven fabrics: Experimental methods and benchmark results. Composites Part A 39:1037-1053. https://doi.org/10.1016/j.compositesa.2008.02.016

32. Yeager M, Cline J, Bogetti T, White K, Sherwood J (2019) Characterization and modeling of the inplane shear deformation in ultra-high molecular weight polyethylene (UHMWPE) composites. Technical Report, DEVCOM Army Research Laboratory, ARL-TP-8791, September 2019

33. Sachs U, Akkerman R (2017) Viscoelastic bending model for continues fiber-reinforced thermoplastic composites in melt". Composites Part A 100:333-341. https://doi.org/10.1016/j.compositesa.2017.05.032

34. Sachs U, Akkerman R, Fetfatsidis K, Vidal-Sallè E, Schumaher J, Ziegmann G, Allaoui S, Hivet G, Maron B, Vanclooster K, Lomov SV (2014) Characterization of the dynamic friction of woven fabrics: Experimental methods and benchmark studies. Composites Part A 67:289-298. https://doi.org/10.1016/j.compositesa.2014.08.026

35. Alshahrani H, Hojjati M (2017) Bending behavior of multilayered textile composite prepregs: Experiment and finite element modeling. Mater Des 124:211-224. https://doi.org/10.1016/j.matdes.2017.03.077

36. Alshahrani $\mathrm{H}$ (2020) Characterization and finite element modeling of coupled properties during polymer composites forming processes. Mech Mater 103370. https://doi.org/10.1016/j.mechmat.2020.103370

37. AniForm Virtual Forming Tool. Software and help-manual.www.aniform.com

\section{Tables 3-4}

Table 3. The material models and parameters in the forming temperatures of the TEPEX Dynalite composite material used for the thermoforming process simulation. 


\begin{tabular}{|c|c|c|c|c|c|}
\hline \multirow[b]{2}{*}{ Element Type } & \multirow[b]{2}{*}{ Constitutive Model } & \multirow[b]{2}{*}{ Parameters } & \multicolumn{2}{|c|}{$\begin{array}{l}\text { TEPEX Dynalite } \\
\text { 104-RG600(x)47\% }\end{array}$} & \multirow[b]{2}{*}{$190^{\circ} \mathrm{C}$} \\
\hline & & & $140^{\circ} \mathrm{C}$ & $160^{\circ} \mathrm{C}$ & \\
\hline \multirow[t]{8}{*}{$\begin{array}{l}\text { Membrane } \\
\text { (In-plane) }\end{array}$} & \multirow[t]{2}{*}{ Elastic Fiber } & $\begin{array}{l}E_{f}[\mathrm{MPa}] \\
\text { orientation }\left[0^{\circ}\right]\end{array}$ & 1000 & 1000 & 1000 \\
\hline & & $\begin{array}{l}E_{f}[\mathrm{MPa}] \\
\text { orientation }\left[90^{\circ}\right]\end{array}$ & 1000 & 1000 & 1000 \\
\hline & \multirow[t]{2}{*}{ Mooney-Rivlin } & $C_{01}[\mathrm{MPa}]$ & 0.048 & 0.012 & 0.005 \\
\hline & & $C_{10}[\mathrm{MPa}]$ & -0.115 & -0.035 & -0.02 \\
\hline & \multirow[t]{4}{*}{ Cross-viscosity fluid } & $\eta_{0}[\mathrm{MPa} \mathrm{s}]$ & 50 & 10 & 1.6 \\
\hline & & $\eta_{\infty}[\mathrm{MPa} s]$ & 0.05 & 0.01 & 0.02 \\
\hline & & $n$ & 0 & 0 & 0 \\
\hline & & $m$ & 517 & 425 & 75 \\
\hline \multirow{6}{*}{$\begin{array}{l}\text { DKT } \\
\text { (Bending) }\end{array}$} & \multirow[t]{2}{*}{ Isotropic Hooke } & $E[\mathrm{MPa}]$ & $1 e-16$ & $1 e-16$ & $1 e-16$ \\
\hline & & $n_{i}$ & 0 & 0 & 0 \\
\hline & \multirow[t]{4}{*}{ Cross-viscosity fluid } & $\eta_{0}[\mathrm{MPa} \mathrm{s}]$ & 100000 & 30000 & 15000 \\
\hline & & $\eta_{\infty}[\mathrm{MPa} \mathrm{s}]$ & 53 & 16 & 11 \\
\hline & & $n$ & 0 & 0 & 0 \\
\hline & & $m$ & 33000 & 32550 & 38224 \\
\hline \multirow{4}{*}{$\begin{array}{l}\text { Contact } \\
\text { Elements }\end{array}$} & \multirow{4}{*}{$\begin{array}{l}\text { Penalty with polymer friction } \\
\text { model (tool\&ply)/ } \\
\text { Coloumb-viscous friction }\end{array}$} & $\mu$ & 100 & 0.297 & 0.143 \\
\hline & & $\eta_{0}[\mathrm{MPa} \mathrm{s}]$ & 1 & 0.0189 & 0.0048 \\
\hline & & $\begin{array}{l}\text { Film thickness } \\
{[\mathrm{mm}] / \mathrm{h} / \mathrm{t}}\end{array}$ & 0.1 & 0.1 & 0.1 \\
\hline & & $\begin{array}{l}\text { Penalty stiffness } \\
E_{p}\left[\mathrm{~N} / \mathrm{mm}^{3}\right]\end{array}$ & 10 & 10 & 10 \\
\hline
\end{tabular}

Table 4. The material models and parameters in the forming temperatures of the Celanese Celstran composite material used for the thermoforming process simulation. 


\begin{tabular}{|c|c|c|c|c|c|}
\hline \multirow[b]{2}{*}{ Element Type } & \multirow[b]{2}{*}{ Constitutive Model } & \multirow[b]{2}{*}{ Parameters } & \multicolumn{2}{|c|}{$\begin{array}{l}\text { Celanese Celstran } \\
\text { CFR-TP PA6 GF60-1 }\end{array}$} & \multirow[b]{2}{*}{$280^{\circ} \mathrm{C}$} \\
\hline & & & $240^{\circ} \mathrm{C}$ & $260^{\circ} \mathrm{C}$ & \\
\hline \multirow[t]{7}{*}{$\begin{array}{l}\text { Membrane } \\
\text { (In-plane) }\end{array}$} & Elastic Fiber & $\begin{array}{l}E_{f}[\mathrm{MPa}] \\
\text { orientation }\left[0^{\circ}\right]\end{array}$ & 1000 & 1000 & 1000 \\
\hline & \multirow[t]{2}{*}{ Isotropic Elastic } & Young [MPa] & 0.017 & 0.011 & 0.009 \\
\hline & & Poisson [v] & 0 & 0 & 0 \\
\hline & \multirow[t]{4}{*}{ Cross-viscosity fluid } & $\eta_{0}[\mathrm{MPa} s]$ & 0.03735 & 0.02628 & 0.025 \\
\hline & & $\eta_{\infty}[\mathrm{MPa} \mathrm{s}]$ & 0.0019 & 0.002 & 0.0011 \\
\hline & & $n$ & 0.1087 & 0.12684 & 0.1332 \\
\hline & & $m$ & 5.2463 & 6.2253 & 9.2961 \\
\hline \multirow{5}{*}{$\begin{array}{l}\text { DKT } \\
\text { (Bending) }\end{array}$} & \multirow[t]{4}{*}{ Orthotropic Elastic } & Young E1 [MPa] & 19 & 19 & 17 \\
\hline & & Young E2 [MPa] & 0.19 & 0.19 & 0.17 \\
\hline & & Poisson $N u_{12}$ & 0.01 & 0.01 & 0.01 \\
\hline & & Shear $G_{12}[\mathrm{MPa}]$ & 0.019 & 0.019 & 0.017 \\
\hline & Newtonian Fluid & $n[\mathrm{MPa} s]$ & 4.5873 & 3.1301 & 2.7084 \\
\hline \multirow{4}{*}{$\begin{array}{l}\text { Contact } \\
\text { Elements }\end{array}$} & \multirow{4}{*}{$\begin{array}{l}\text { Penalty with polymer } \\
\text { friction model (tool\&ply)/ } \\
\text { Coloumb-viscous friction }\end{array}$} & $\mu$ & 0.02816 & 0.02816 & 0.02816 \\
\hline & & $\eta_{0}[\mathrm{MPa} \mathrm{s}]$ & 0.00317 & 0.00208 & 0.00119 \\
\hline & & $\begin{array}{l}\text { Film thickness } \\
{[\mathrm{mm}] / \mathrm{h} / \mathrm{t}}\end{array}$ & 0.1 & 0.1 & 0.1 \\
\hline & & $\begin{array}{l}\text { Penalty stiffness } \\
E_{p}\left[\mathrm{~N} / \mathrm{mm}^{3}\right]\end{array}$ & 10 & 10 & 10 \\
\hline
\end{tabular}

\section{Figures}




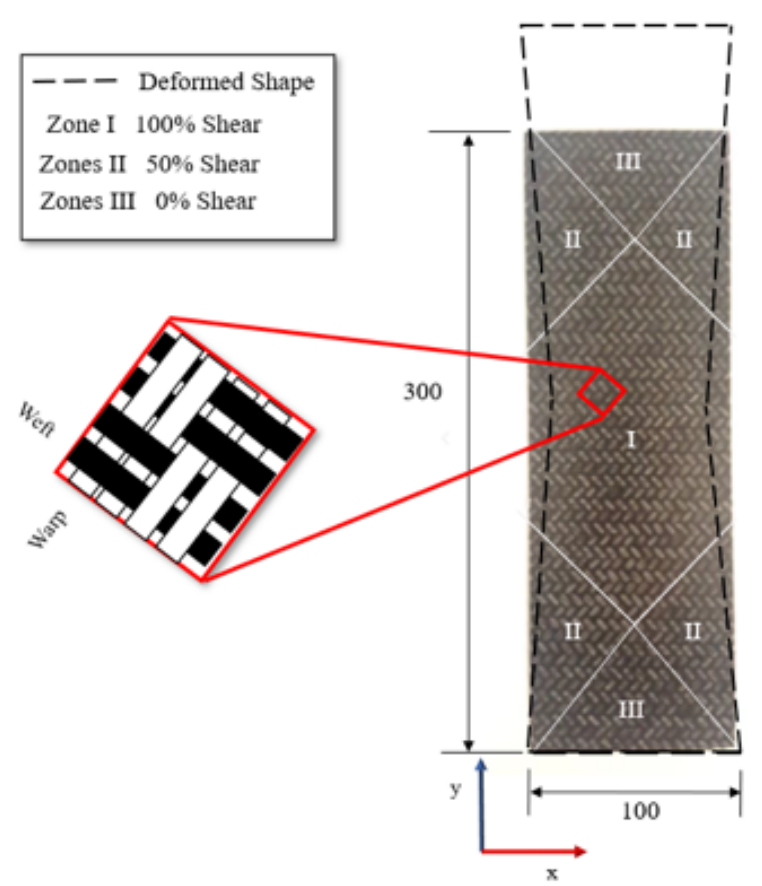

(a)

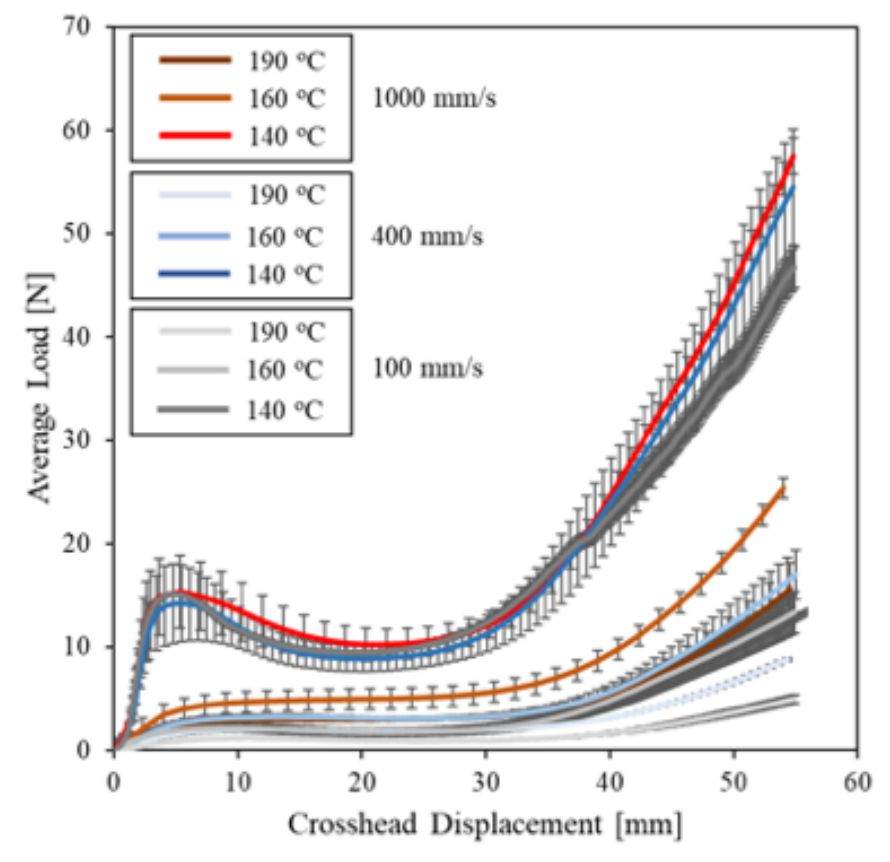

(b)

\section{Figure 1}

Basic geometry and characteristics of the bias extension test (a) and the Average Load-Crosshead Displacement curves in various temperatures and testing speeds 


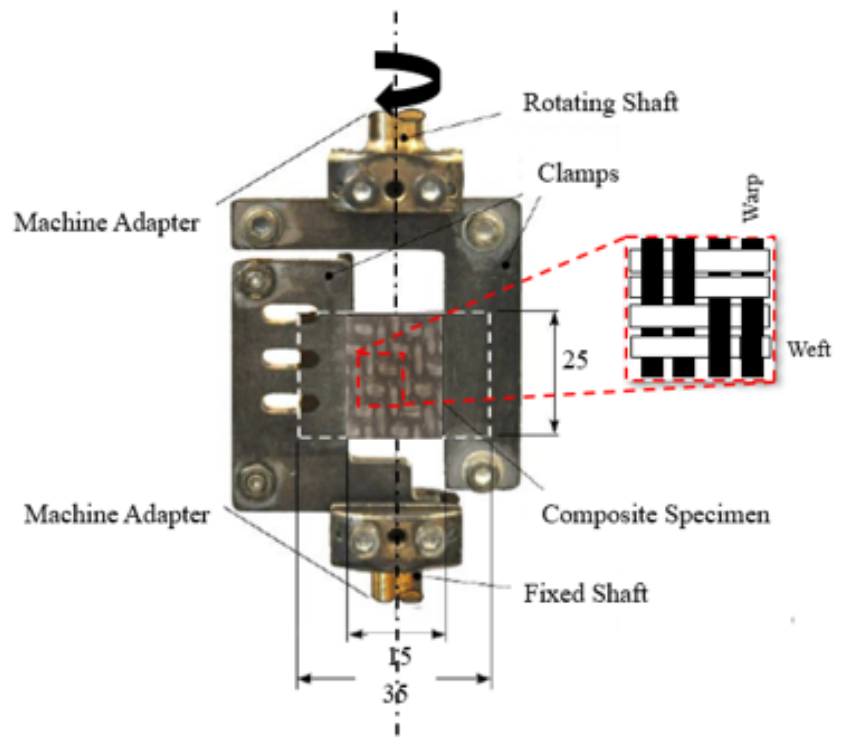

(a)

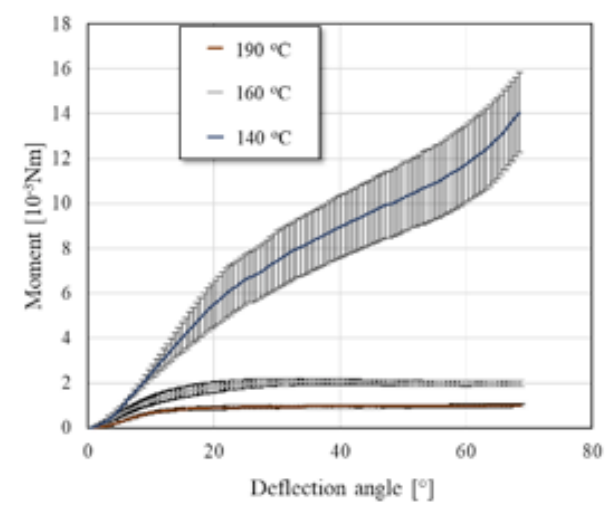

(b)

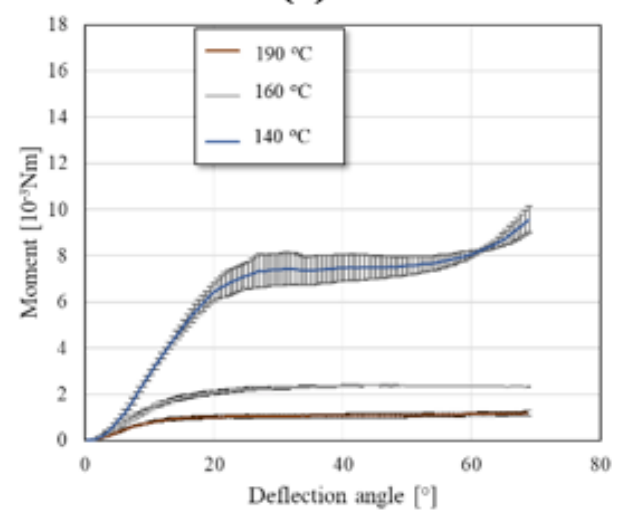

(c)

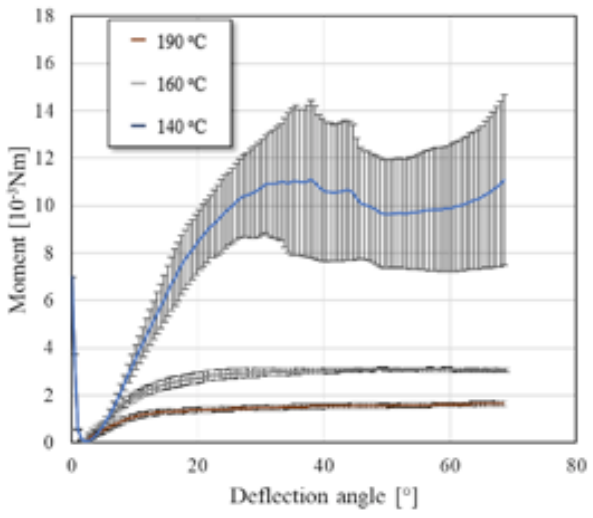

(d)

\section{Figure 2}

The configuration of the implemented bending tests (a) and the average Moment-Deflection Angle obtained by the tests at 0.1 (b), 1 (c) and 10 (d) rpm, respectively. 

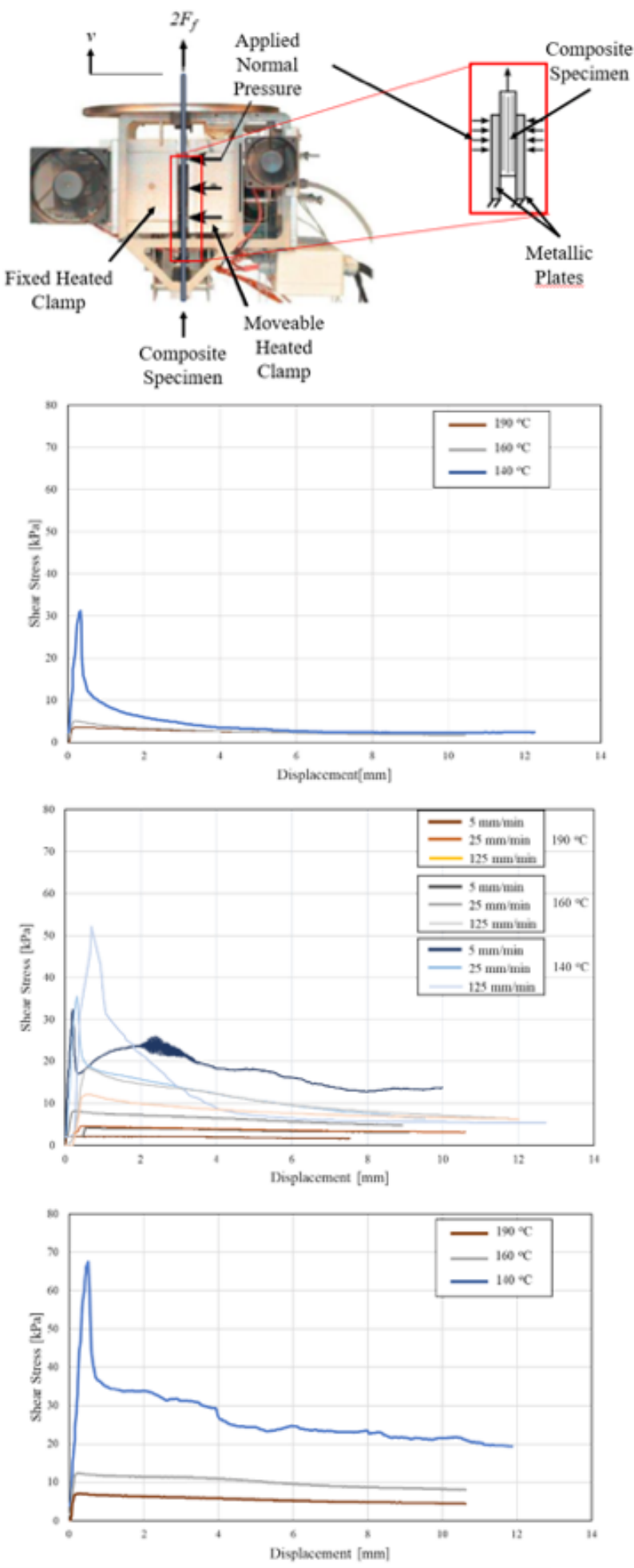

(a)

(b)

(c)

(d)

\section{Figure 3}

The dynamic friction test principals and basic dimensions (a) and the Shear Stress-Displacement curves in various temperatures for applied pressure of $5 \mathrm{kPa}$ (b), $15 \mathrm{kPa}$ (c) and $45 \mathrm{kPa}$ (d). 

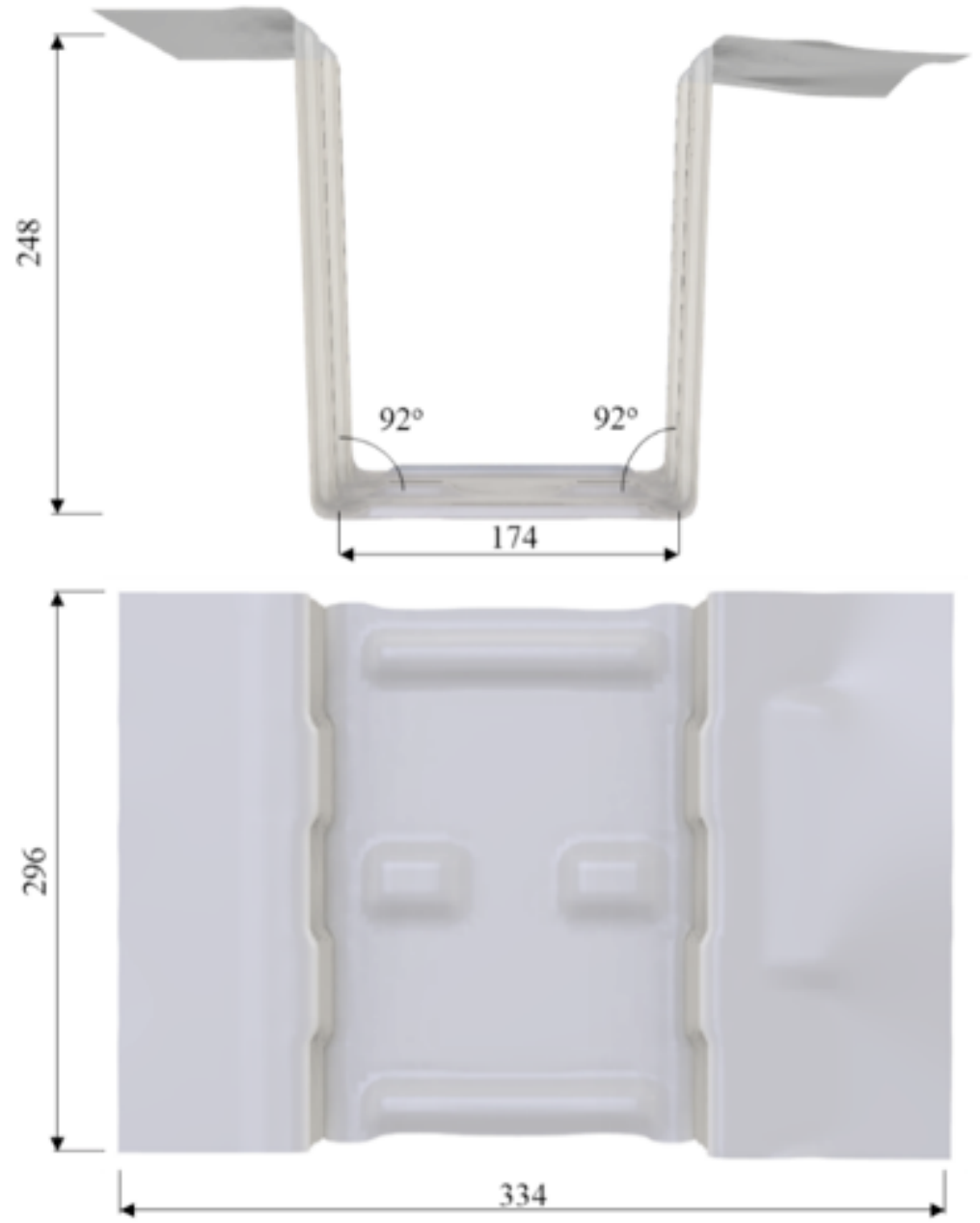

Figure 4

The geometry and basic dimensions of the composite component. 
(a)

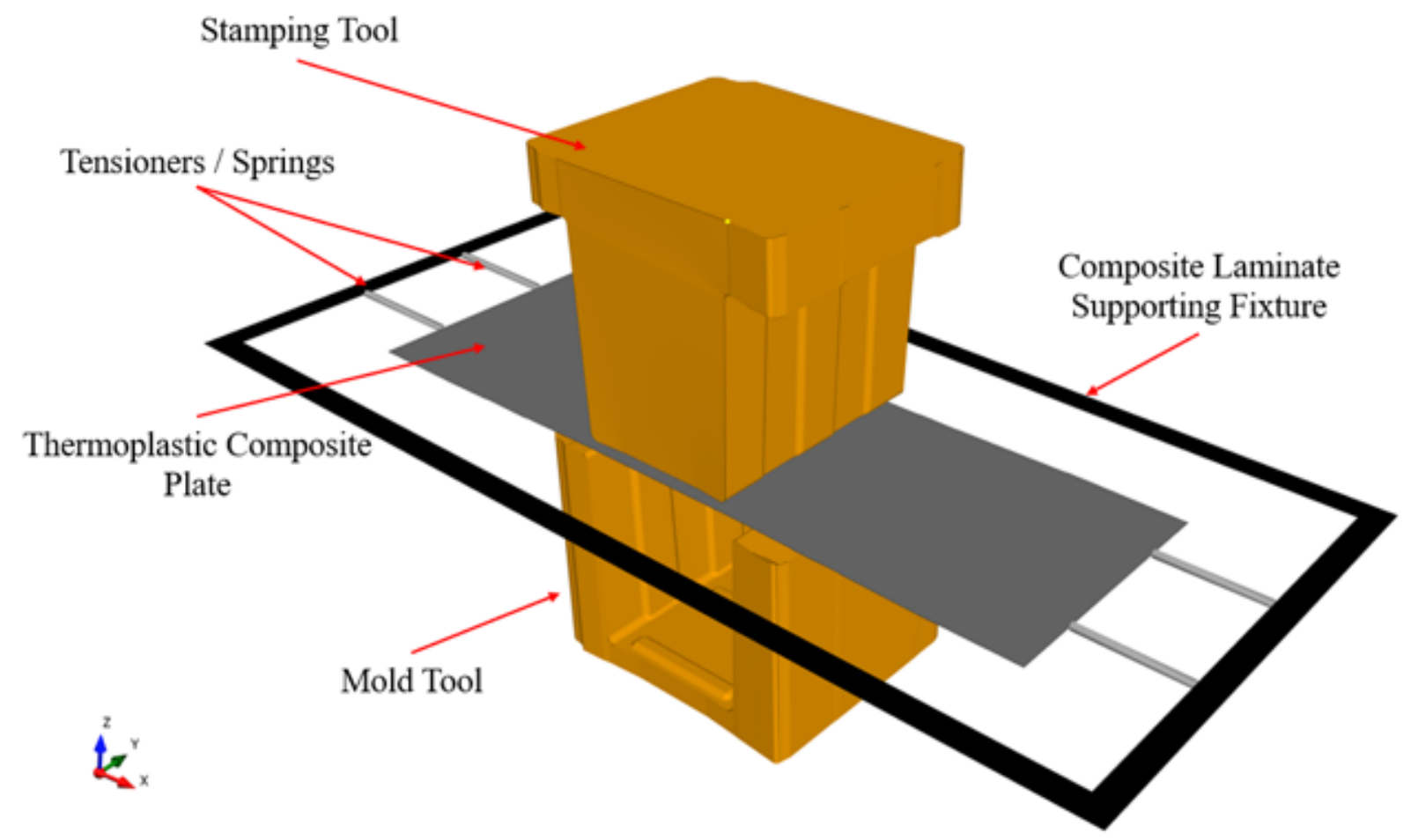

(b)

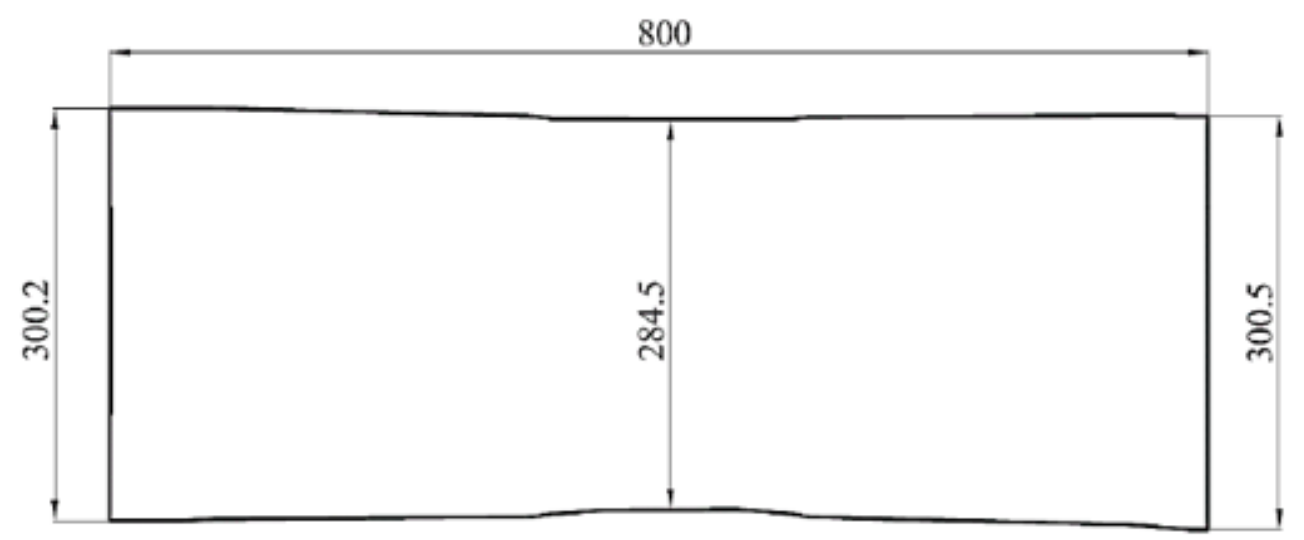

Figure 5

The parts developed for the thermoforming simulation in CATIA V5 (a) and the dimensions of the composite plate (b). 
(a)

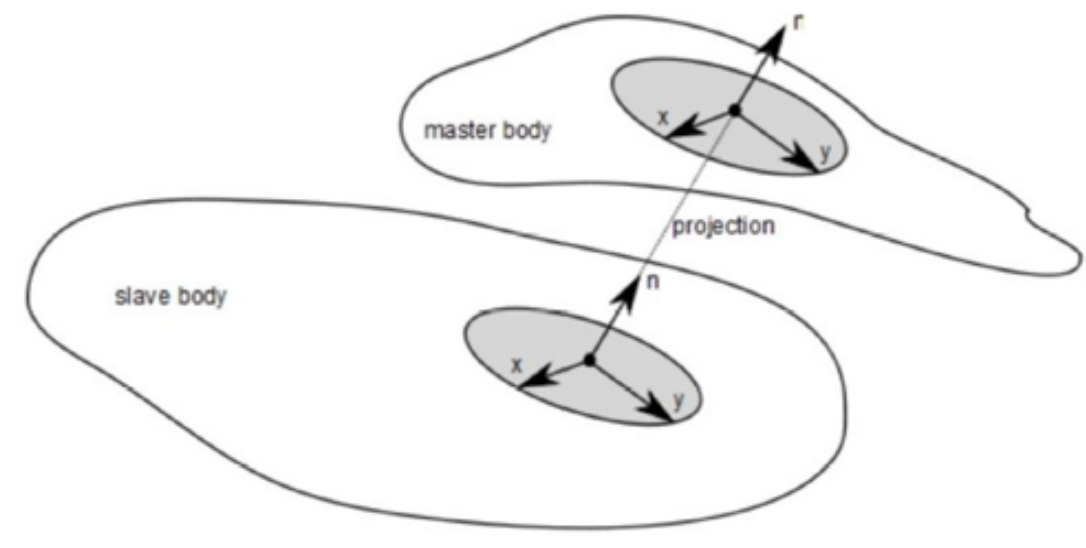

No contact

Contact

(b)

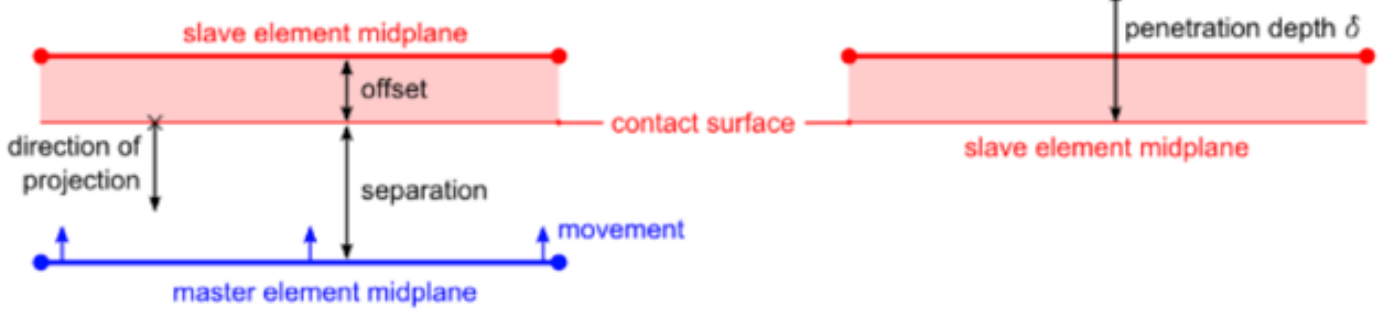

\section{Figure 6}

Explanation of the projection process for creating contact between surfaces (a) and schematic representation the offset process (b) both as seen in the FE software manual [37].

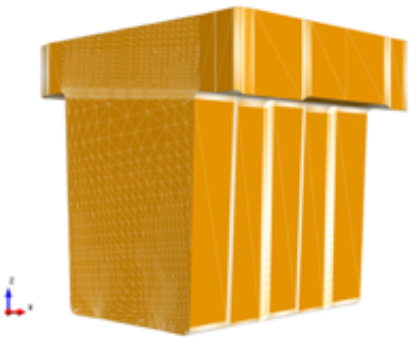

Stamping Tool
L.

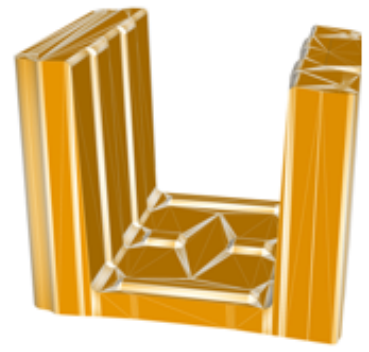

Mold Tool

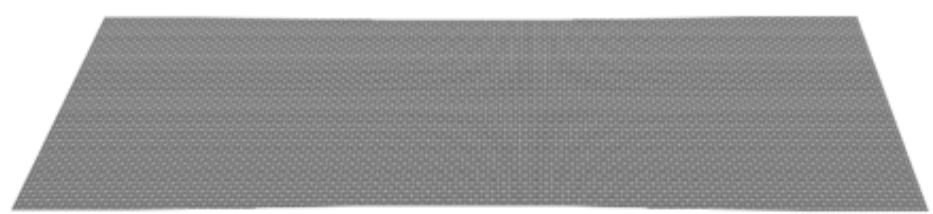

L.

\section{Composite Plate}

\section{Figure 7}

Mesh discretization of the stamping tools and the composite plate 

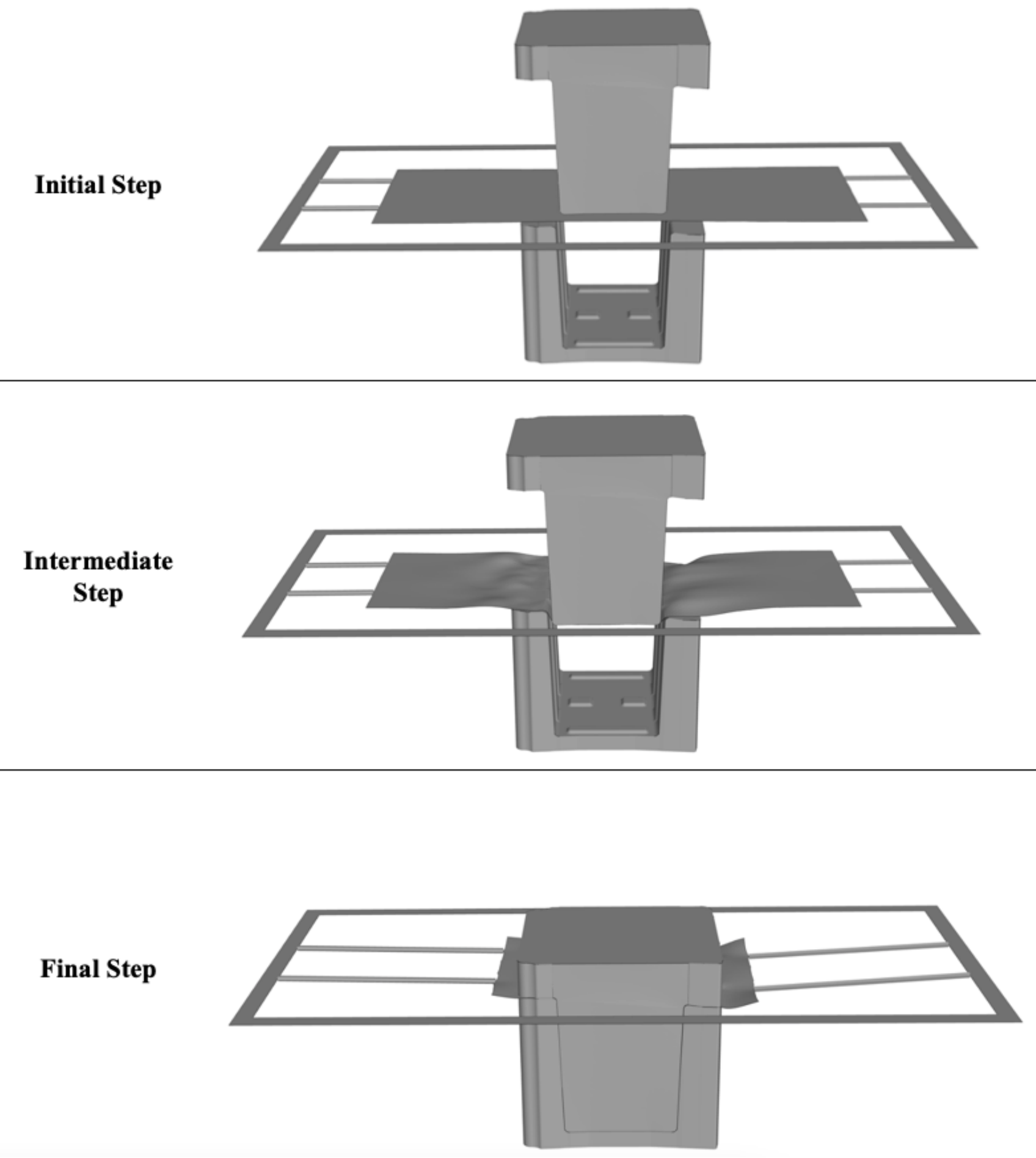

Figure 8

Frames taken during various steps of the thermoforming process of the box-shaped geometry. 


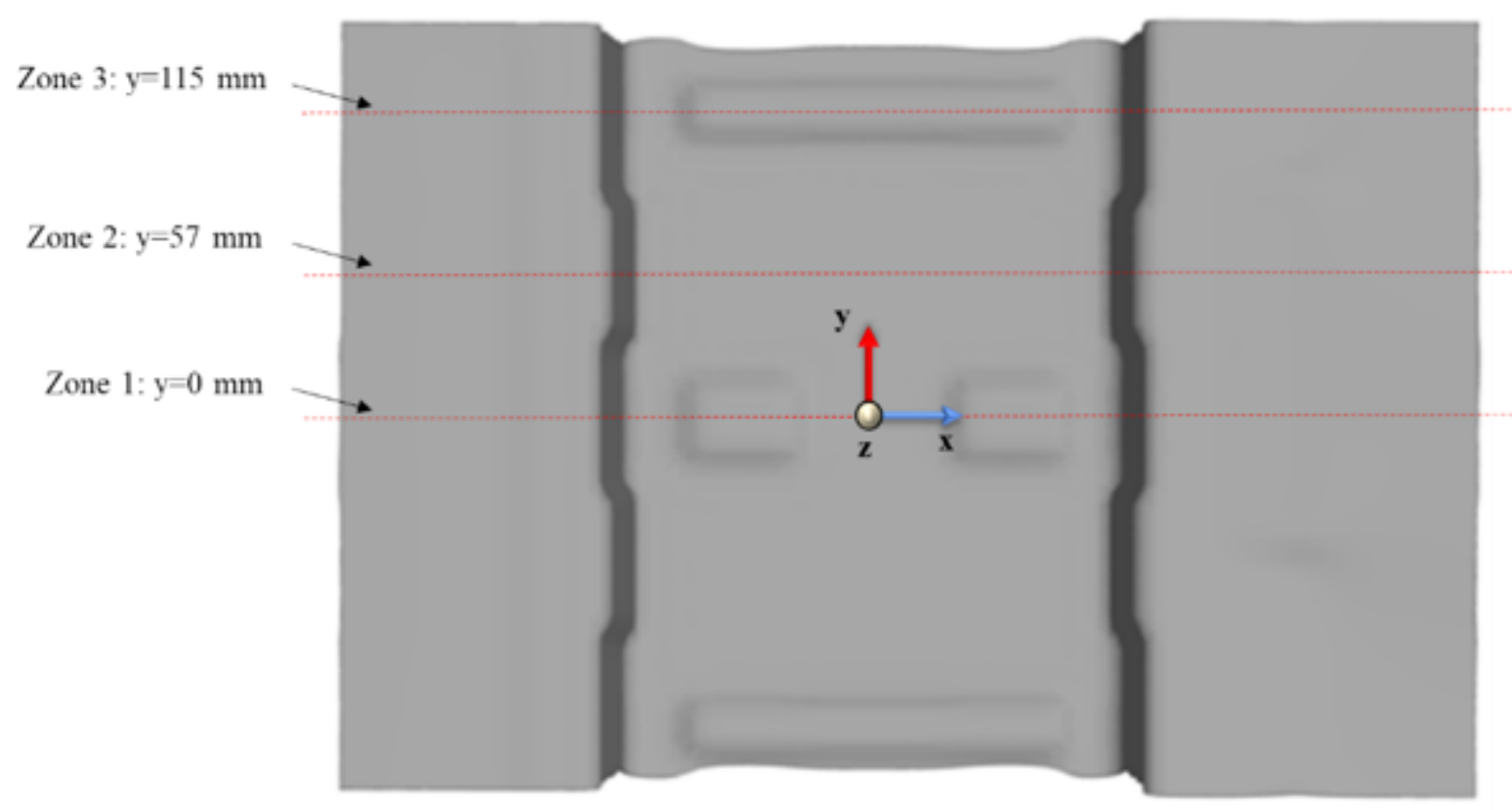

\section{Figure 9}

The coordinates of each of the 6 local zones selected for studying the distribution of various results

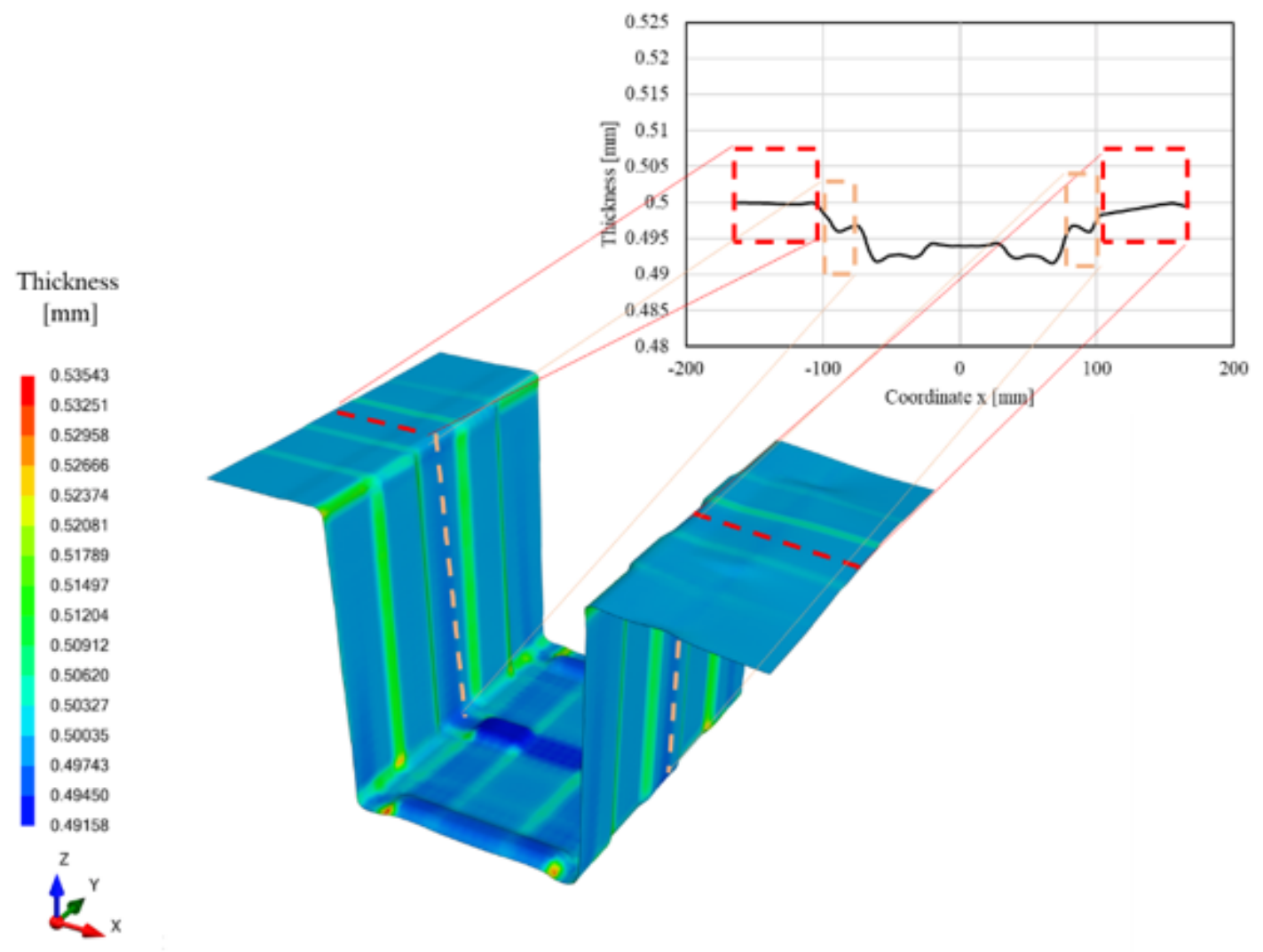

Figure 10 
Typical example of the correspondence of the thickness variation with the parts of the Zone 1 for the case of the 2-2 twill weave/PP composite material.

TEPEX Dynalite

104-RG600(x)47\%

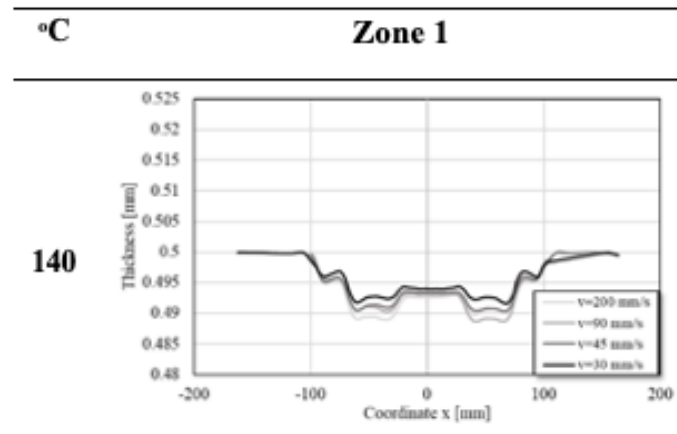

Zone 2

Zone 3
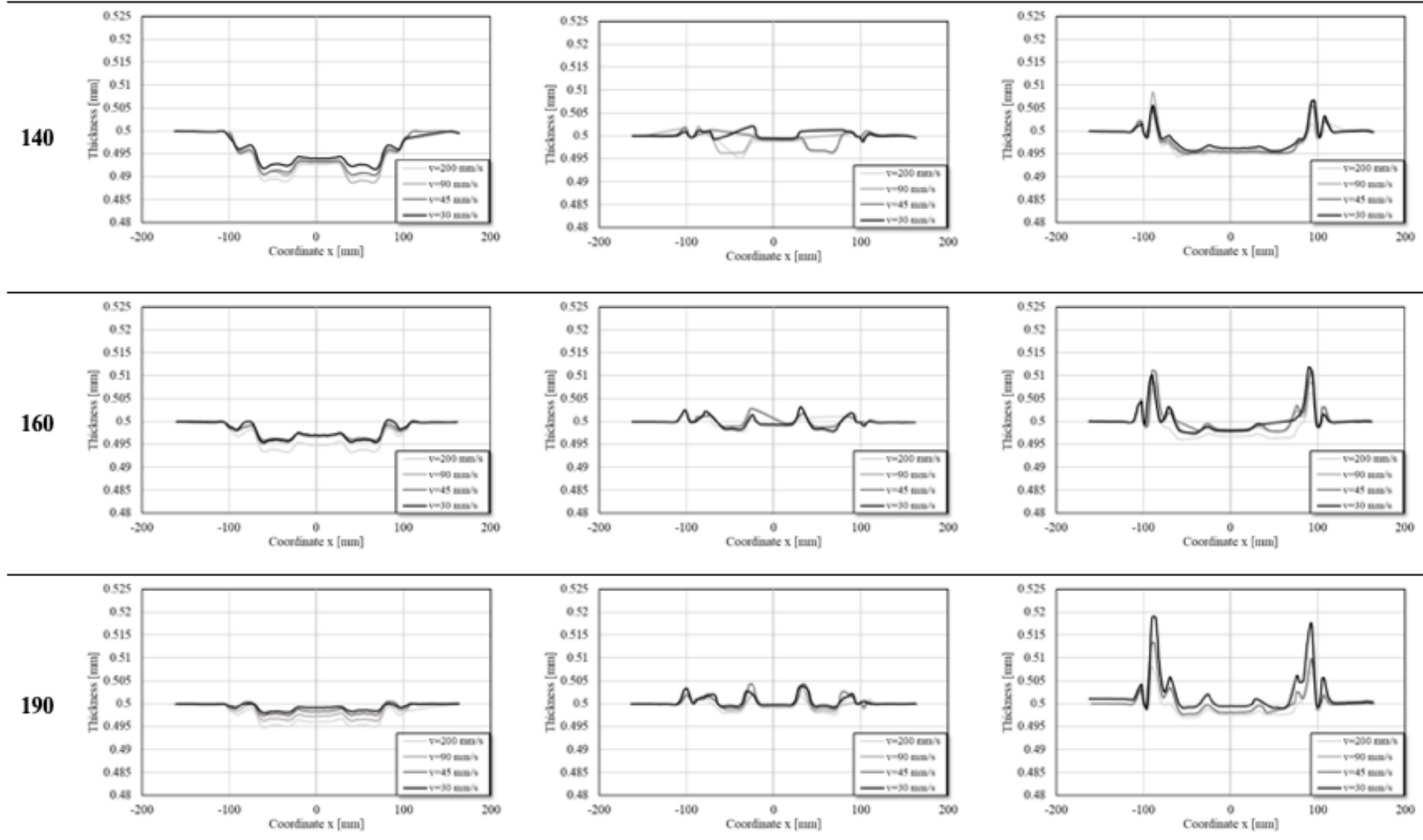

\section{Figure 11}

The variation of thickness in the three zones of interest for all the temperatures and crosshead speeds using the TEPEX Dynalite 104-RG600(x)47\% material. 


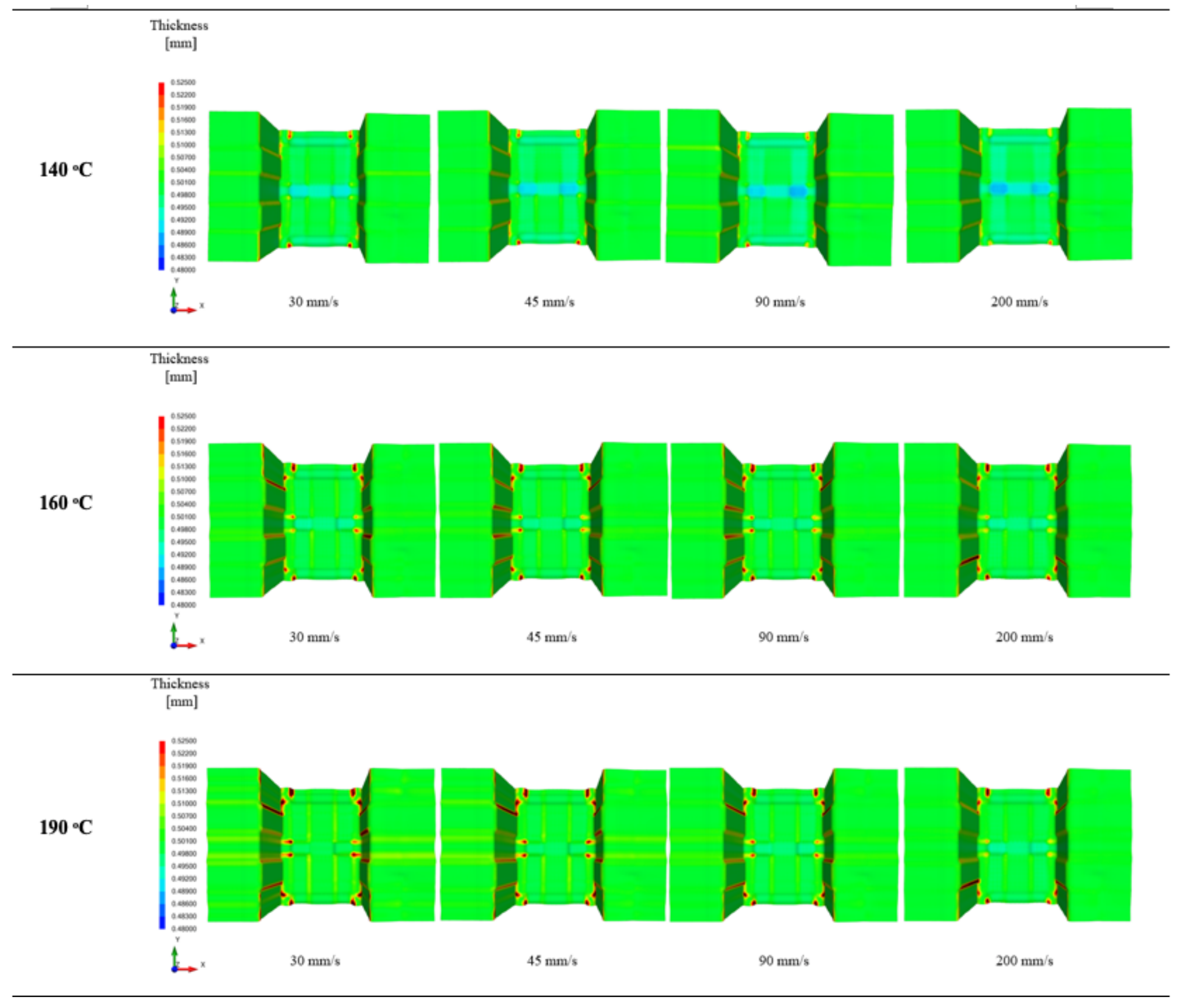

\section{Figure 12}

The plot of the thickness variation of the component as obtained by the FE analysis using the TEPEX Dynalite 104-RG600(x)47\% 


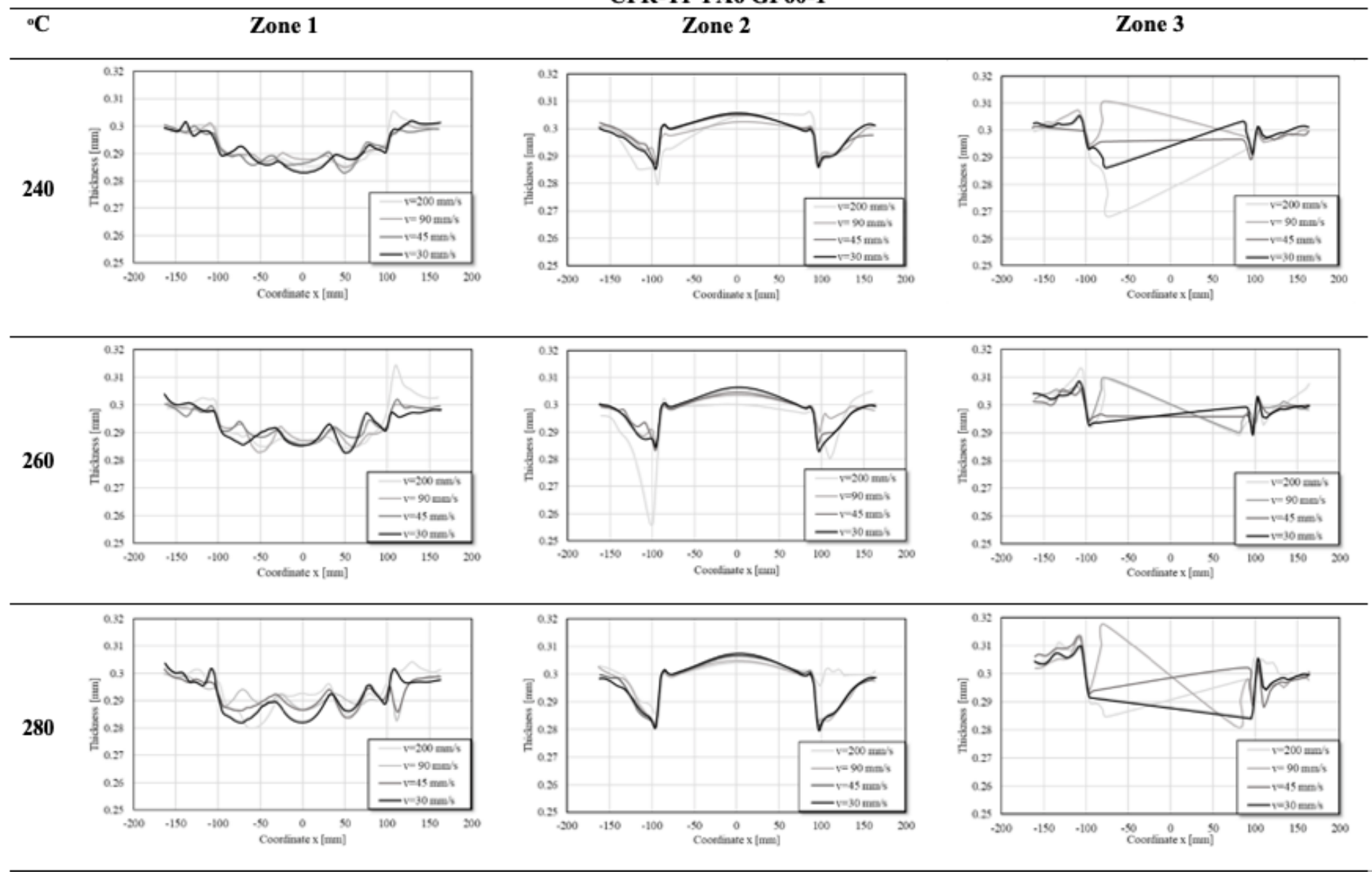

\section{Figure 13}

The variation of thickness in the three zones of interest for all the temperatures and crosshead speeds using the UD Celanese Celstran CFR-TP PA6 GF60-1 material. 


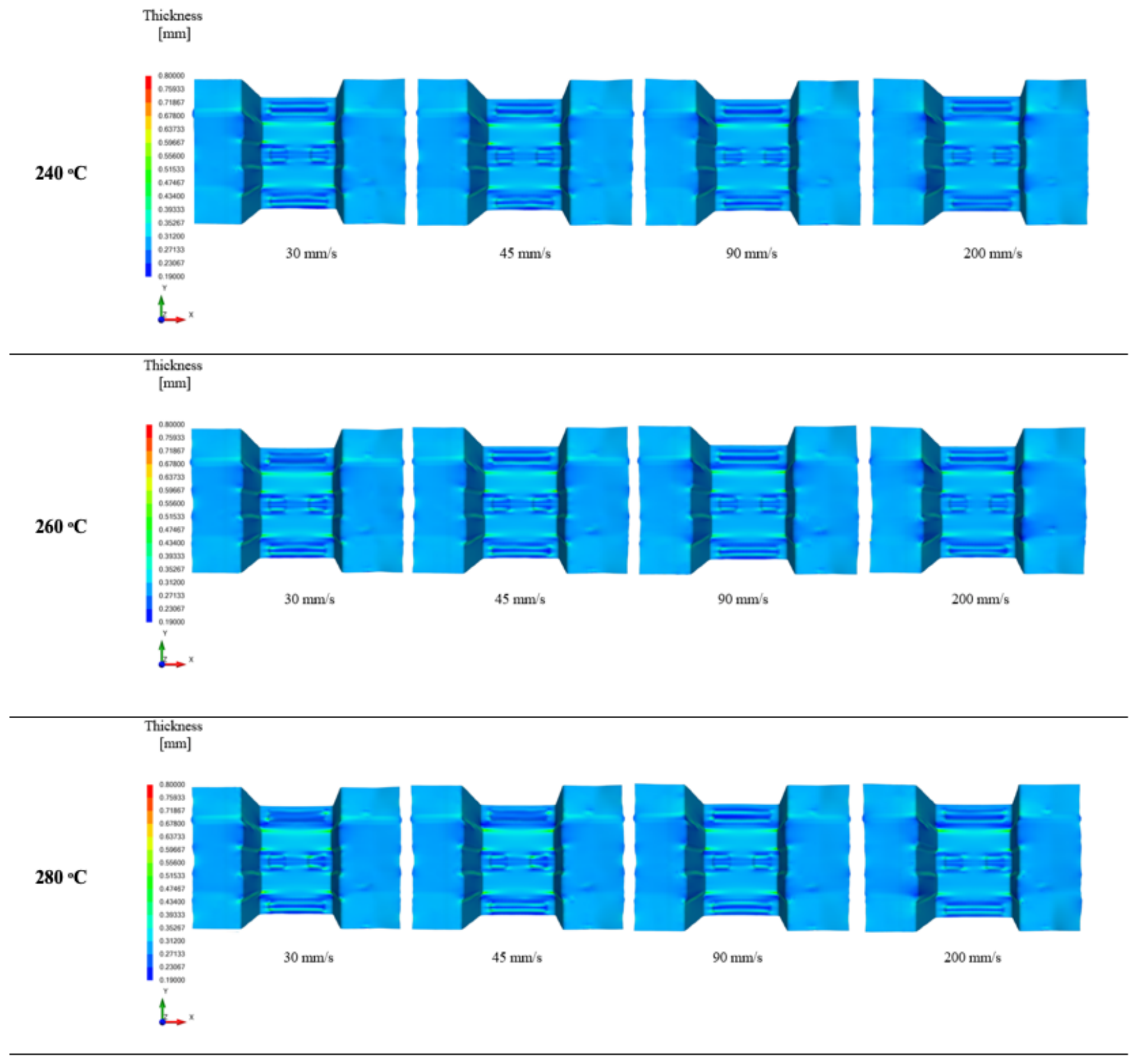

\section{Figure 14}

The plot of the thickness variation of the component as obtained by the FE analysis using the Celanese Celstran CFR-TP PA6 GF60-1 

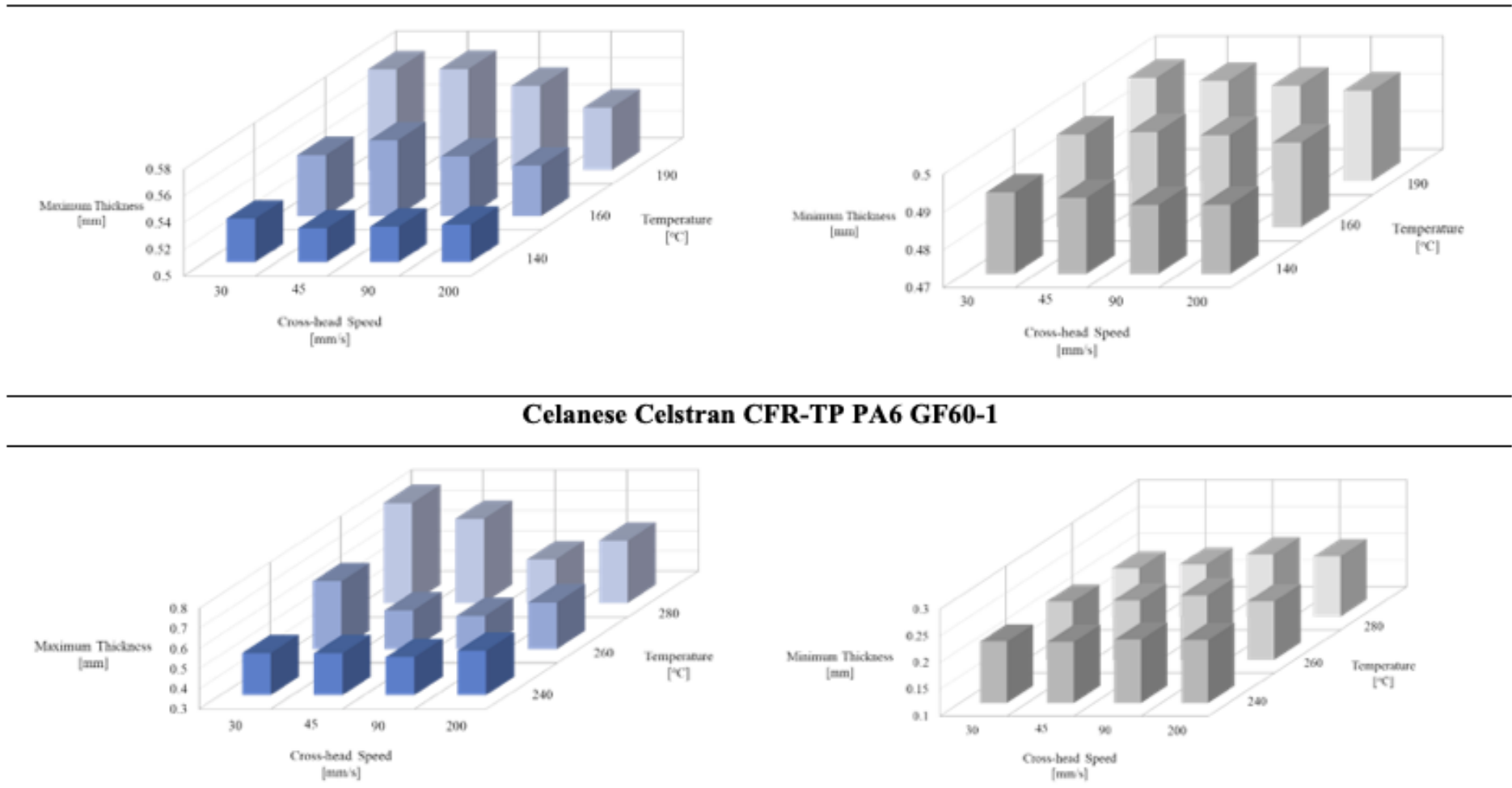

Figure 15

The maximum and minimum values of thickness obtained by the FE analyses for varying crosshead speeds and temperatures for the 2 materials of interest 
TEPEX Dynalite 104-RG600(x)47\%

$140{ }^{\circ} \mathrm{C}-30 \mathrm{~mm} / \mathrm{s}$
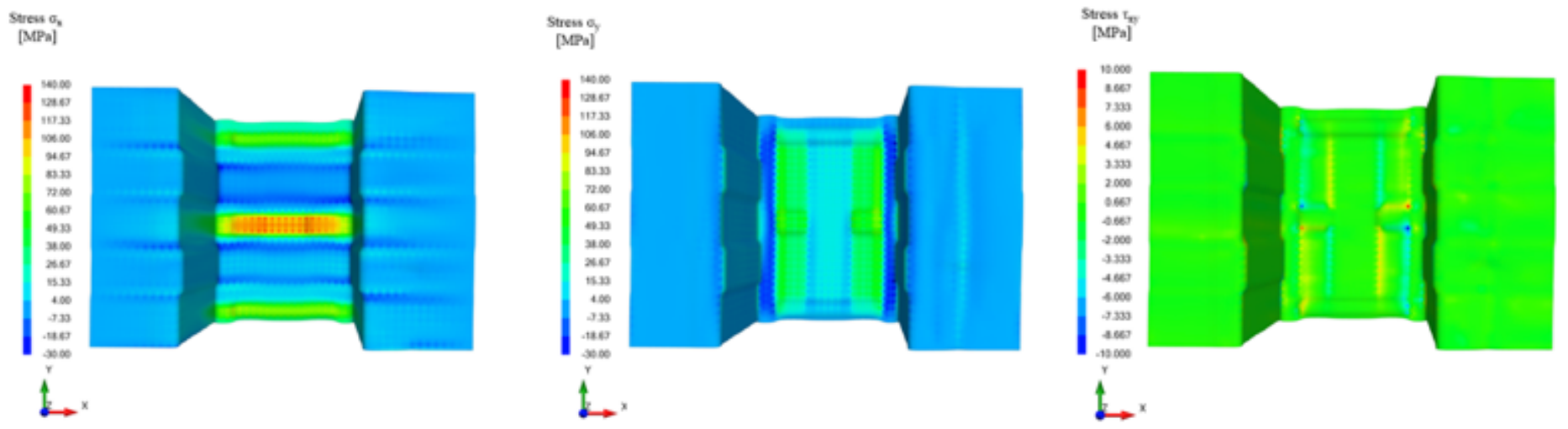

\section{Celanese Celstran CFR-TP PA6 GF60-1}

$$
240{ }^{\circ} \mathrm{C}-30 \mathrm{~mm} / \mathrm{s}
$$

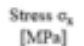

Stees $\sigma_{\text {, }}$

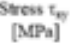
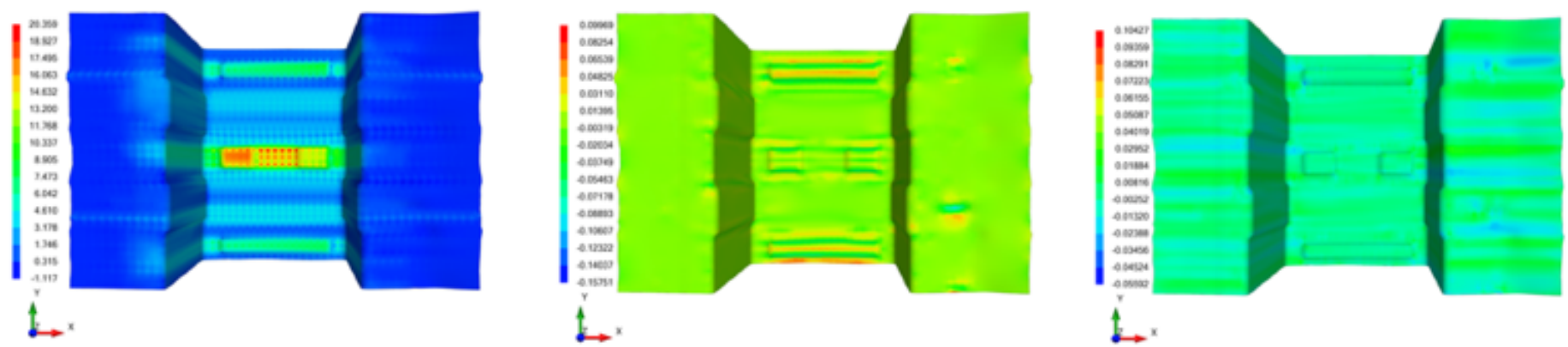

Figure 16

Typical distribution of the normal and shear stresses field obtained by the simulation of the textile material and UD composite materials. 


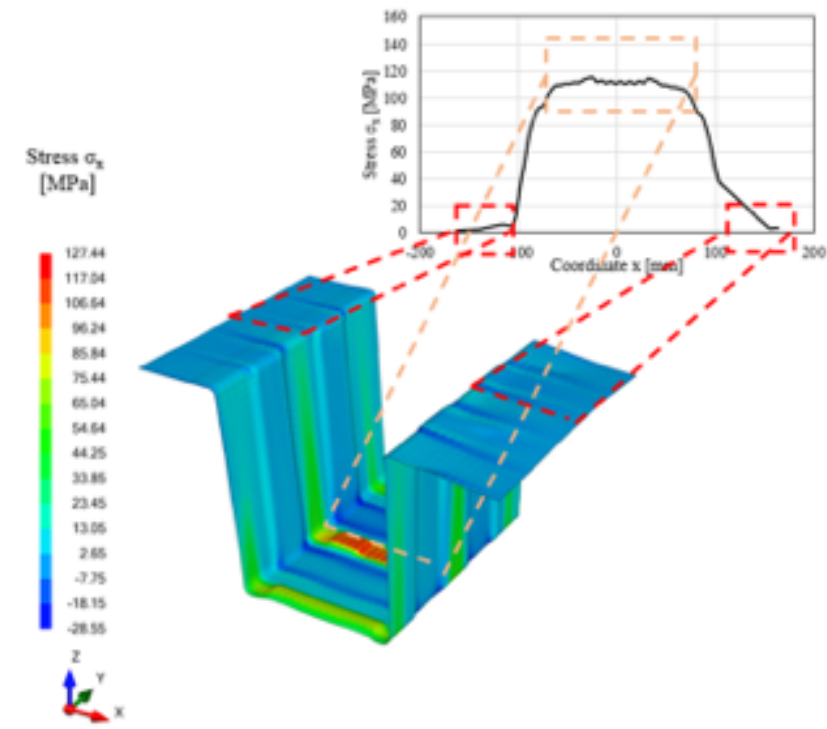

(a)

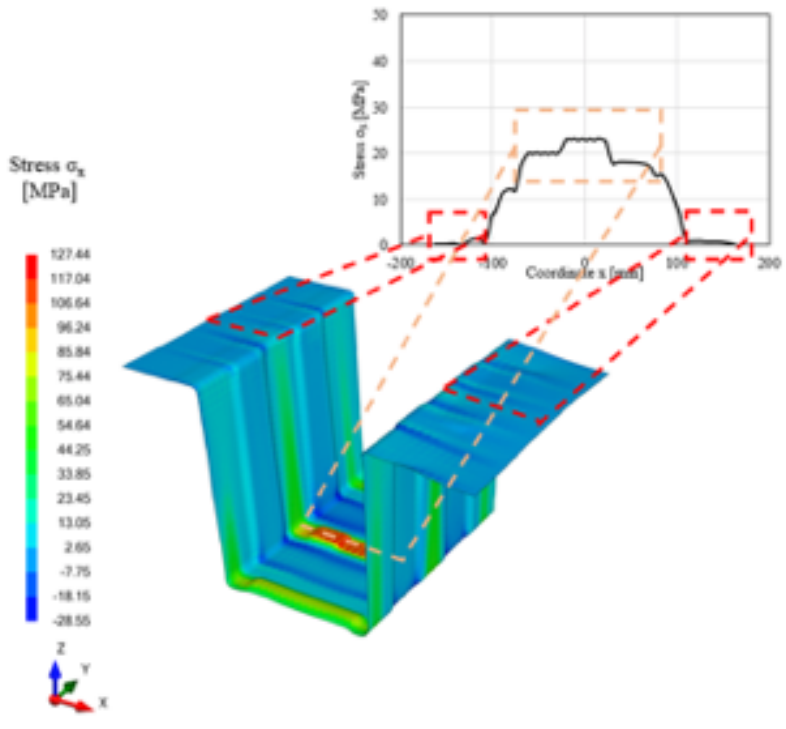

(b)

Figure 17

The normal stress $\sigma x$ distribution and analysis of the distribution of the stresses in the central zone (Zone

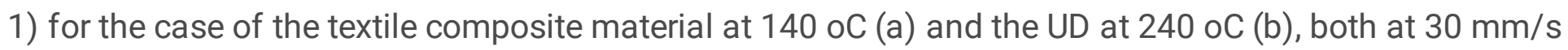
crosshead speed.

140
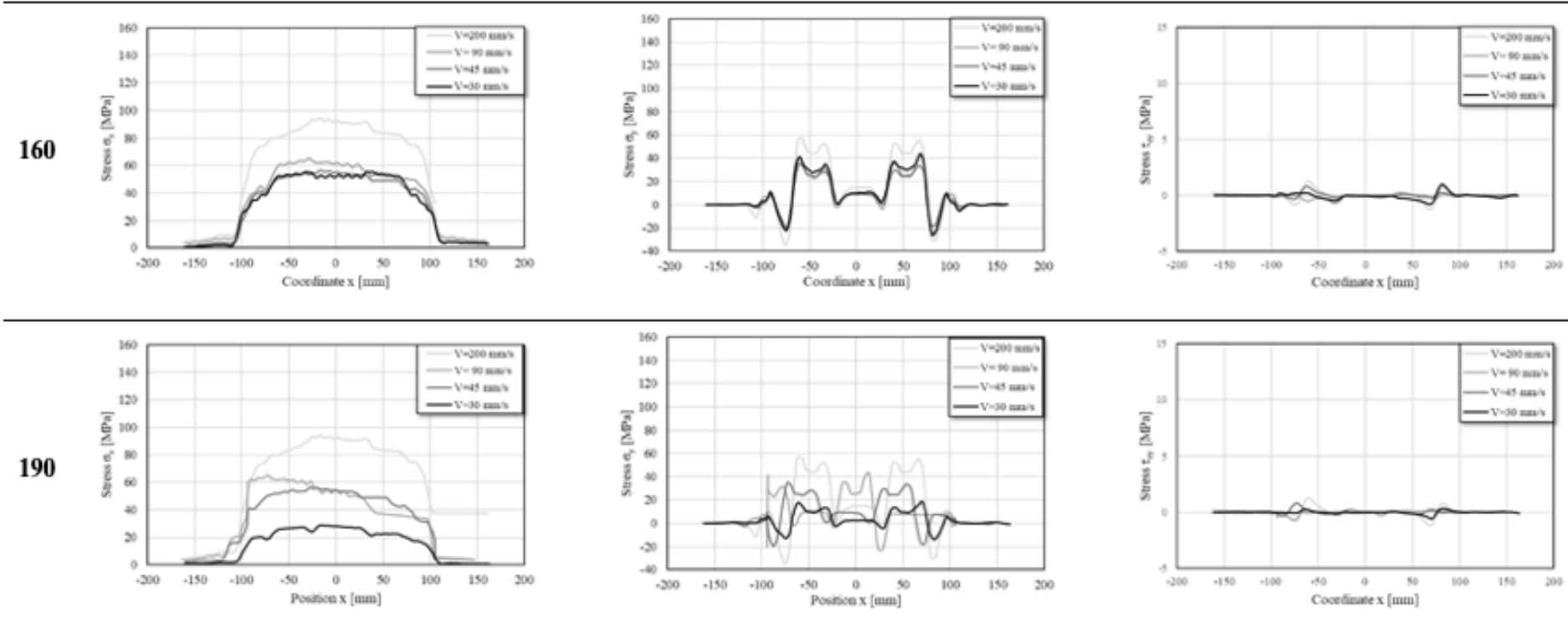
Figure 18

The distribution of the stresses at the central zone (Zone 1) of the component as obtained by the FE simulations in various temperatures for the case of the textile E-glass/PP composite material

Celanese Celstran

CFR-TP PA6 GF60-1

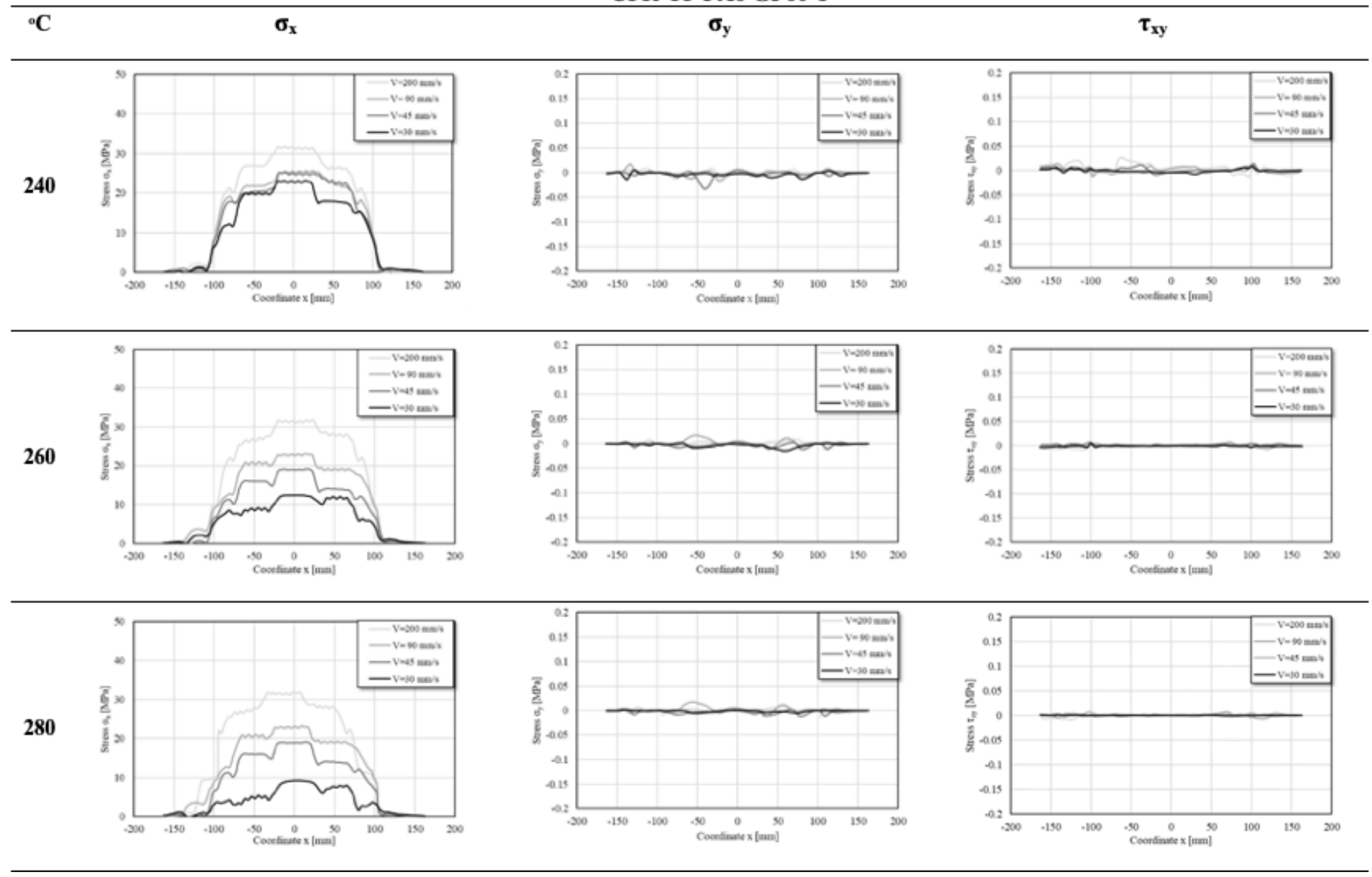

Figure 19

The distribution of the stresses at the central zone (Zone 1) of the component as obtained by the FE simulations in various temperatures for the case of the UD E-glass/PA6 composite material 

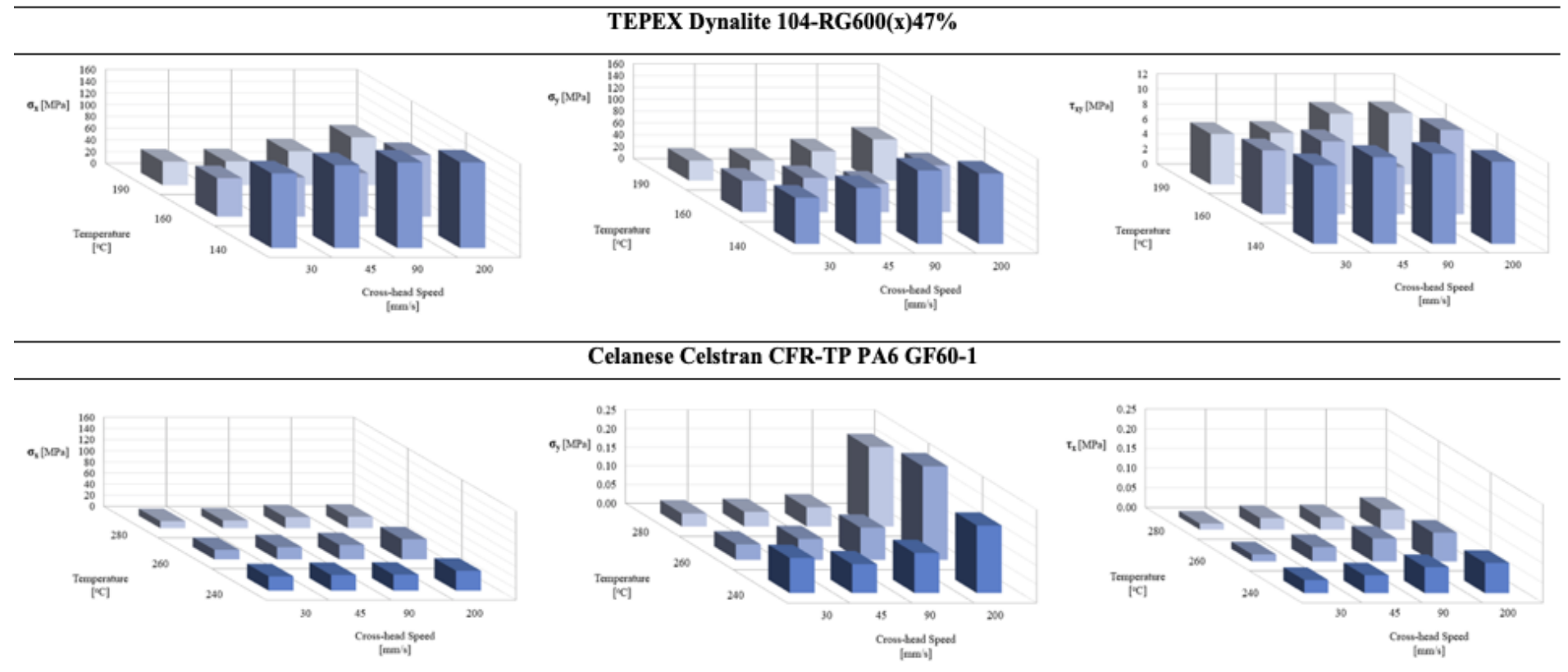

Figure 20

The maximum values of normal and in-plane shear stresses obtained by the FE simulation of the thermoforming using the TEPEX Dynalite 104-RG600(x)47\% and the Celanese Celstran CFR-TP PA6 GF60-1.

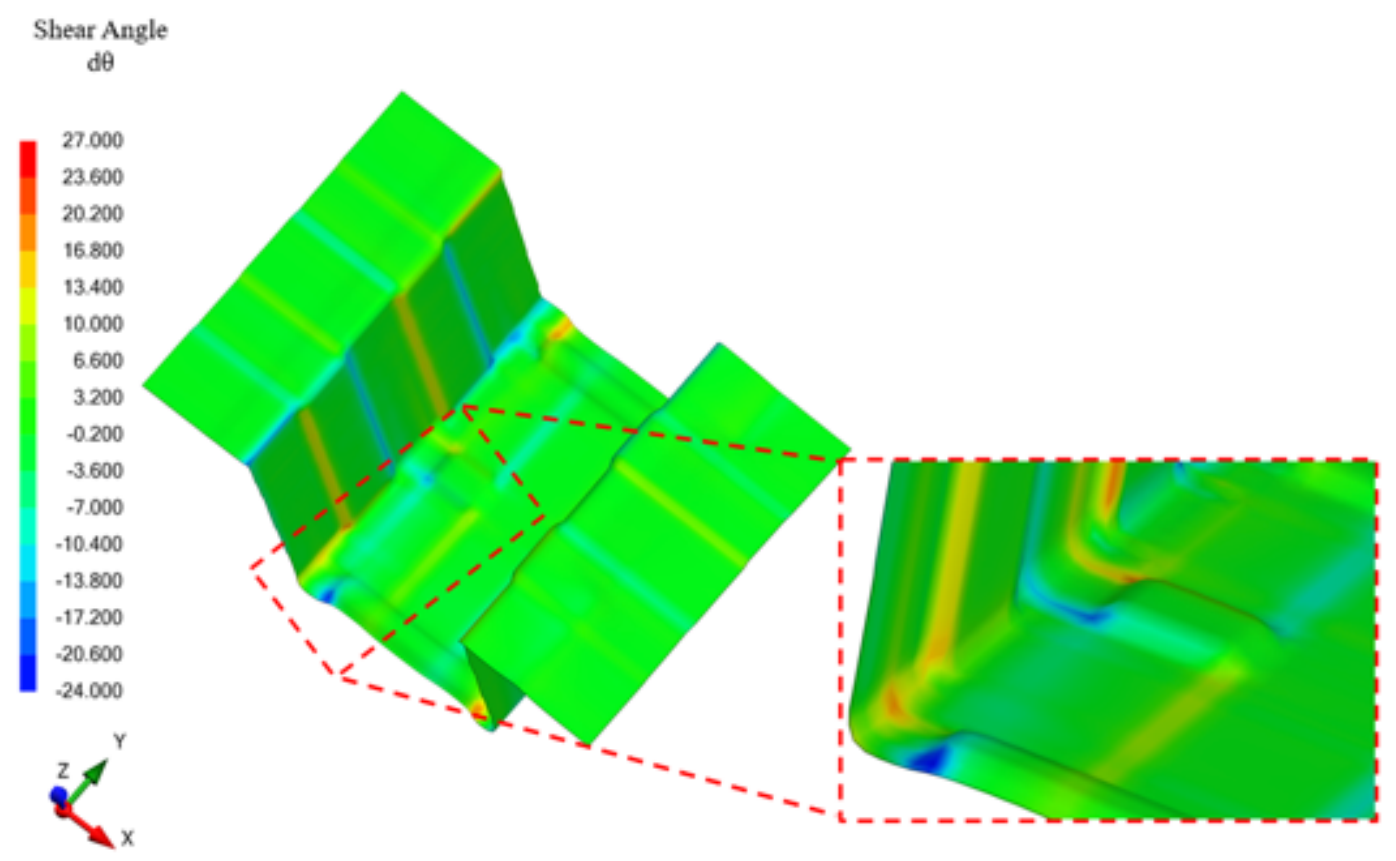

\section{Figure 21}

The shear angle distribution as obtained by the simulation of the textile material at $140 \mathrm{oC} / 30 \mathrm{~mm} / \mathrm{s} \mathrm{FE}$ simulation. 


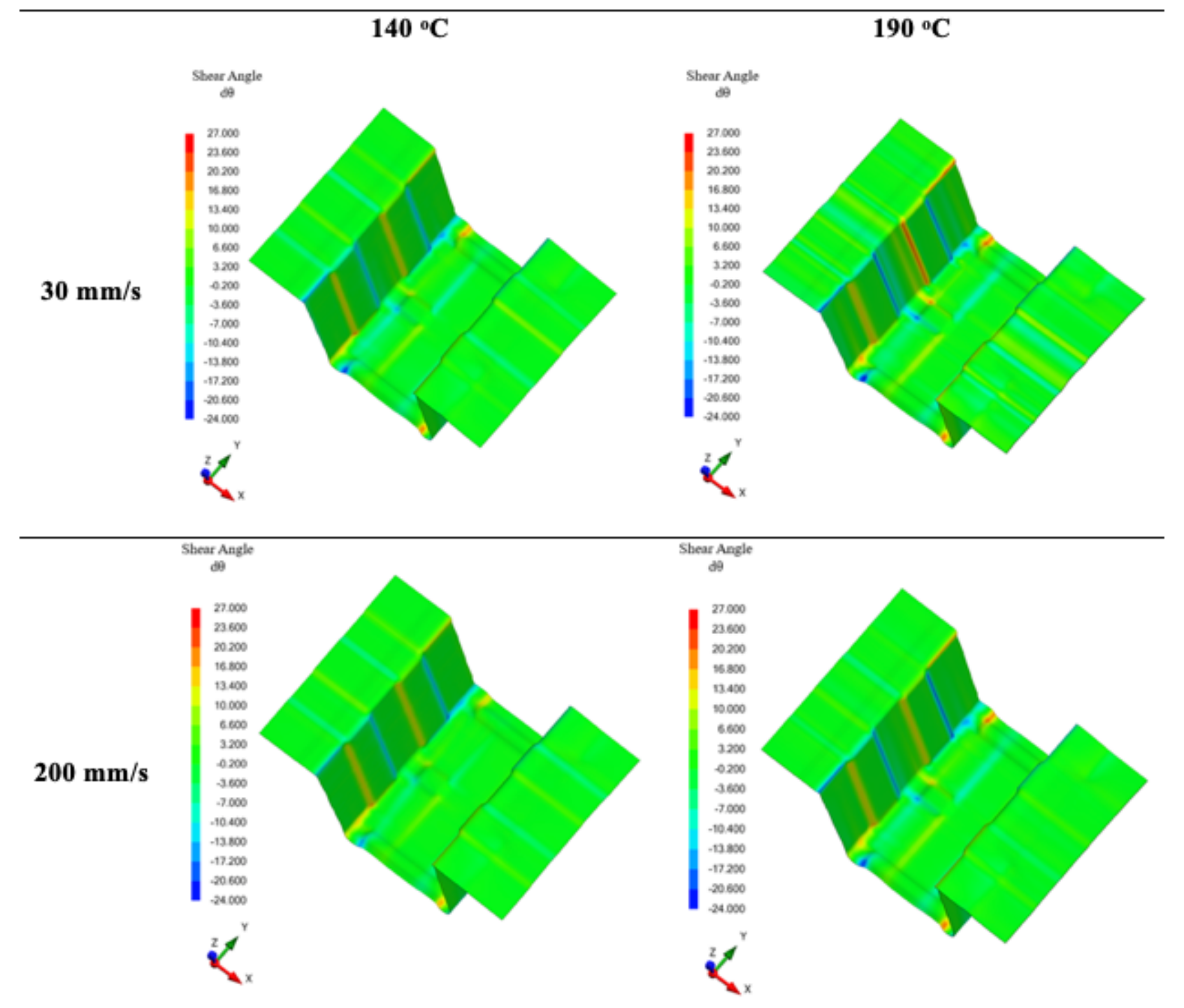

Figure 22

Comparison of the shear angle $\mathrm{d} \theta$ distribution at various stamping speed and temperatures. 